\title{
ARTICLE OPEN Priming with FLO8-deficient Candida albicans induces Th1- biased protective immunity against lethal polymicrobial sepsis
}

Quan-Zhen Lv ${ }^{1,2}$, De-Dong Li ${ }^{1}$, Hua Han ${ }^{1}$, Yi-Heng Yang ${ }^{1}$, Jie-Lin Duan ${ }^{1}$, Hui-Hui Ma ${ }^{1}$, Yao Yu ${ }^{1}$, Jiang-Ye Chen ${ }^{3}$, Yuan-Ying Jiang ${ }^{1}$ and Xin-Ming Jia (D) ${ }^{1}$

The morphological switch between yeast and hyphae of Candida albicans is essential for its interaction with the host defense system. However, the lack of understanding of host-pathogen interactions during C. albicans infection greatly hampers the development of effective immunotherapies. Here, we found that priming with the C. albicans FLO8-deficient (flo8) mutant, locked in yeast form, protected mice from subsequent lethal C. albicans infection. Deficiency of Dectin-2, a fungus-derived a-mannan recognition receptor, completely blocked flo8 mutant-induced protection. Mechanistically, the flo8 mutant-induced Dectin-2/ CARD9-mediated IL-10 production in DCs and macrophages to block thymus atrophy by inhibiting the C. albicans-induced apoptosis of thymic T cells, which facilitated the continuous output of naive T cells from the thymus to the spleen. Continuous recruitment of naive T cells to the spleen enhanced Th1-biased antifungal immune responses. Consequently, depletion of CD4+ T cells or blockade of IL-10 receptor function using specific antibodies in mice completely blocked the protective effects of flo8 mutant priming against $C$. albicans infection. Moreover, mannans exposed on the surface of the flo8 mutant were responsible for eliciting protective immunity by inhibiting the $C$. albicans-induced apoptosis of thymic $T$ cells to sustain the number of naive $T$ cells in the spleen. Importantly, priming with the flo8 mutant extensively protected mice from polymicrobial infection caused by cecal ligation and puncture (CLP) by enhancing Th1-biased immune responses. Together, our findings imply that targeting FLO8 in C. albicans elicits protective immune responses against polymicrobial infections and that mannans extracted from the flo 8 mutant are potential immunotherapeutic candidate(s) for controlling infectious diseases.

Keywords: Fungi infection; Candida albicans; Protective immunity; Thymus atrophy; Apoptosis

Cellular \& Molecular Immunology (2021) 18:2010-2023; https://doi.org/10.1038/s41423-020-00576-6

\section{INTRODUCTION}

Sepsis is the systemic inflammatory response syndrome caused by bacterial, viral, or fungal infections. ${ }^{1}$ Although hundreds of clinical trials have been conducted, no effective new therapies against sepsis have been approved. Invasive fungal infections, especially candidemia, have become a major cause of morbidity and mortality in the past few decades, and these fungi are difficult to target pharmacologically. Accumulating evidence supports that effective therapies against invasive fungal infections require the development of immunotherapeutic strategies, which could be combined with antifungal chemotherapy. ${ }^{2,3}$ Recent studies have shown that vaccination with live attenuated vaccines such as Bacillus Calmette-Guérin, the measles vaccine, the oral polio vaccine, or commensal intestinal fungi such as Candida albicans and Saccharomyces cerevisiae can protect the host from infections caused by various species of microorganisms, ${ }^{4-6}$ which makes it possible to develop immunopotentiators or vaccines against polymicrobial sepsis from attenuated pathogens or human commensal microorganisms. For $C$. albicans, a leading commensal fungal pathogen affecting humans, the transition between yeast and hyphal forms is critical for its pathogenicity in life-threatening invasive candidiasis, and this disease has a high mortality rate, exceeding $40 \% .^{7-9}$ Current studies show that $C$. albicans yeast cells are suitable for early colonization and dissemination, while hyphal forms are required for tissue penetration and organ-seated infection. Therefore, most C. albicans mutants locked in either morphological state are less virulent in mouse bloodstream infection models. ${ }^{10}$ Inhibiting fungal morphological transformation is an important means of inhibiting fungal virulence and immune escape. However, despite intense research efforts, the development of efficient antifungal immunotherapies has fallen behind in part due to an insufficient understanding of the host-pathogen interactions and the mechanisms underlying immune escape and the induction of protective immunity during fungal infections.

The transcription factor Flo8p is known to be essential for hyphal development in C. albicans, and the flo 8 null mutant kept in yeast form is hypovirulent in the bloodstream infection mouse model. ${ }^{11}$ However, we found that the flo8 null (flo8) mutant was fully virulent in a systemic candidiasis mouse model deficient for caspase recruitment domain family member 9 (CARD9), which is well known to operate downstream of several immunoreceptor

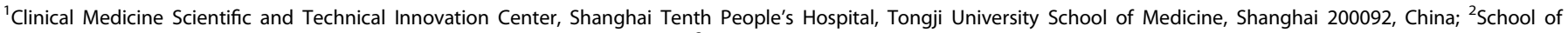

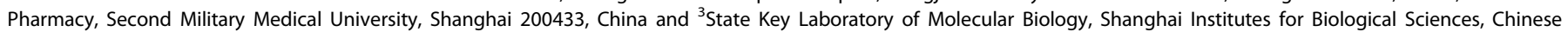
Academy of Sciences, Shanghai 200031, China

Correspondence: Xin-Ming Jia (jiaxm@tongji.edu.cn) or Yuan-Ying Jiang (13761571578@163.com)
}

Received: 29 June 2020 Accepted: 14 October 2020

Published online: 5 November 2020 
tyrosine-based activation motif-associated C-type lectin receptors (CLRs), including Dectin-1, Dectin-2, and Dectin-3, to mediate antifungal immune responses in mice and humans. ${ }^{12-16}$ Therefore, we hypothesize that the flo 8 mutant shapes host immune responses toward a host-protective type. In this case, the flo 8 mutant may elicit immune responses to protect hosts from subsequent lethal infection. Our findings suggested that the flo 8 mutant is an effective immunopotentiator for controlling polymicrobial sepsis and that mannans extracted from this mutant might provide potential immunotherapeutic candidate(s) for controlling infectious diseases.

\section{RESULTS}

Priming with the flo8 mutant protects mice from C. albicans infection through Dectin-2

Consistent with previous studies, ${ }^{11,17}$ disruption of the FLO8 gene in C. albicans completely blocked the serum-induced yeast-tohyphae transition at $37^{\circ} \mathrm{C}$ (Fig. S1A). Furthermore, infection with the flo8 mutant did not result in any fatality in wild-type mice for up to 30 days (Fig. 1A). However, infected mice failed to completely clear the flo8 mutant in the kidney, liver, and spleen for up to 21 days (Fig. 1C), suggesting that the flo 8 mutant is a hypovirulent strain. However, we surprisingly observed that the flo8 mutant had strong pathogenicity in CARD9-deficient mice (Fig. 1A, B). These data suggest that the attenuated virulence of the flo 8 mutant in wild-type mice may have been due to the activation of CARD9-mediated protective immune responses. These protective benefits indicated that priming with the flo 8 mutant may protect the host against a subsequent lethal infection.

To examine the above hypothesis, we employed the priming strategy with two inoculations spaced at an interval of 14 days, as shown in Fig. 1D. All mice primed with the flo8 mutant $\left(5 \times 10^{5}\right.$ CFUs) survived for more than 30 days after infection with the fully virulent C. albicans strain SC5314 (Fig. 1E). Consistently, priming with the flo8 mutant significantly reduced the kidney fungal load in mice after reinfection with C. albicans (Fig. 1E). However, priming with the efg $1 / \mathrm{cph} 1$ mutant, which was also locked in yeast form, ${ }^{18,19}$ slightly increased the survival of infected mice (Fig. 1E). When the interval of inoculation was decreased to 7 days (Fig. 1F), sufficient induction of immune protection by the flo 8 mutant was observed (Fig. 1G, H). In contrast, priming with the efg $1 / \mathrm{cph} 1$ mutant had no protection against $C$. albicans reinfection (Fig. 1G). Moreover, when the interval of inoculation was decreased to 3 days, priming with the flo 8 mutant had no protection against C. albicans reinfection (Fig. S1B).

To determine whether the protection of the C. albicans mutant was controlled by Flo8p, mice were primarily challenged with the flo8 mutant or the FLO8 revertant strain $\left(1 \times 10^{5}\right.$ CFUs, Fig. 1I). Priming with a low dose of the flo 8 mutant was partially protective (Fig. 11). However, the FLO8 revertant strain had no protection against $C$. albicans reinfection (Fig. 1I). In addition, the flo8 mutant inactivated by UV or ethanol had no protection (Fig. $1 \mathrm{~J}$ ). Together, these data suggest that the live flo 8 mutant provided dosedependent protection against secondary $C$. albicans infection and that this protection was specifically regulated by Flo8p.

We then examined whether the immunoprotection induced by the flo8 mutant was dependent on subsequent challenge with specific $C$. albicans strains or mouse species. We observed that the flo8 mutant had comparable protective influences on the survival rate after reinfection with clinical $C$. albicans isolate UCA3 or UCA21 (Fig. 1K). Comparable protective benefits induced by the flo8 mutant were also observed in BALB/C and C57BL/6 mice (Fig. 1L). Collectively, these data indicated that priming with the flo8 mutant could protect the host against a subsequent lethal infection, and this protection was independent of the strain or mouse species utilized.
To explore whether the immunoprotection induced by the flo 8 mutant against $C$. albicans infection was mediated by CLR signaling, we utilized mice deficient for Dectin-1, Dectin-2, or Dectin-3. We found that Dectin-2 deficiency completely blocked flo8 mutant-induced protection, resulting in a significantly lower survival rate of mice after $C$. albicans infection than that of control mice (Fig. 1M). However, deficiency of Dectin-1 or Dectin-3 had no significant influence on flo8 mutant-induced protection (Fig. 1M). Together, these data implied that priming with the flo 8 mutant protected mice from C. albicans infection through Dectin-2.

Priming with the flo 8 mutant blocks $C$. albicans-induced thymus atrophy by inhibiting T-cell apoptosis

Severe thymus atrophy, largely reflecting intense lymphocyte depletion caused by massive cortical T-cell apoptosis, is commonly observed in a variety of acute infections, including viral diseases, bacterial infections, and fungal infections. ${ }^{20-22}$ Here, we observed a persistent and significant decrease in thymus size and weight until death in mice infected with a lethal dose of $C$. albicans (Fig. 2A, B). Histological examination of thymuses from infected mice revealed a marked disappearance of lymphocytes from the thymic cortex (Fig. 2C). These data suggest that C. albicans infection induced irreversible thymus atrophy in mice. However, we surprisingly found that priming with the flos mutant completely prevented mice infected with $C$. albicans from thymus atrophy, as the thymuses of these mice were comparable in size, weight, and cortical lymphocyte appearance to those in uninfected mice (Fig. 2B, C). To determine whether the protective responses induced by the flo8 mutant were dependent on the thymus, we prechallenged athymic nude mice or mice, which lack mature $T$ and $B$ cells, with deficiency of recombination-activating gene 1 (RAG1). We observed that priming with the flo8 mutant had no protection against $C$. albicans infection in nude or RAG1deficient mice (Fig. 2D). These data indicate that the thymus is required for the protective responses induced by the flo 8 mutant.

To further explore the influences of $C$. albicans infection and flo 8 mutant priming on the thymus, we investigated whether $C$. albicans infection selectively affected certain thymocyte subpopulations. Consistent with thymus atrophy, the absolute numbers of immature $\mathrm{CD} 4^{+} \mathrm{CD}^{+}{ }^{+}$cells and mature $\mathrm{CD} 4^{+}$and $\mathrm{CD} 8^{+} \mathrm{T}$ cells were significantly decreased, especially at day 3 after $C$. albicans infection (Figs. $2 \mathrm{E}$ and $\mathrm{S} 2 \mathrm{~A}$ ). However, priming with the flo8 mutant successfully sustained the numbers of $\mathrm{CD} 4^{+} \mathrm{CD} 8^{+}, \mathrm{CD} 4^{+}$, and $C D 8+T$ cells in the thymuses of reinfected mice (Figs. $2 E$ and S2A). Together, these data suggest that priming with the flo8 mutant blocks thymus atrophy by inhibiting decreased T-cell numbers caused by $C$. albicans infection.

It is well documented that a number of bacterial, viral and parasitic infections decrease T-cell numbers through the apoptosis pathway. ${ }^{22}$ To determine whether apoptosis contributes to the loss of T cells, thymus organs were collected from mice to examine the expression of well-characterized apoptosis cell markers, including Annexin V, caspase-3, proapoptotic genes (GILZ, Bim, p53, Bax, Fas, and FasL), and antiapoptotic genes (Bcl2 and BCL$\mathrm{XL}$ ). We found that $C$. albicans infection significantly increased the frequency of Annexin $\mathrm{V}$ and caspase- 3 expression in $\mathrm{CD} 4^{+} \mathrm{CD} 8^{+}$, $\mathrm{CD}^{+}$or $\mathrm{CD} 8+\mathrm{T}$ cells (Figs. $2 \mathrm{~F}$ and $\mathrm{S} 2 \mathrm{~B}, \mathrm{C}$ ) and selectively increased the expression levels of proapoptotic genes, including GILZ, Bim, p53, and FasL, in the thymus (Fig. 2G). In contrast, priming with the flo8 mutant significantly decreased the frequency of Annexin $\mathrm{V}^{+}$and caspase- $3^{+} \mathrm{T}$ cells in infected mice (Figs. $2 \mathrm{~F}$ and $\mathrm{S} 2 \mathrm{~B}, \mathrm{C}$ ). Moreover, this priming significantly reduced the expression of the proapoptotic genes GILZ and Bim and significantly increased the expression of the antiapoptotic genes BCL-2 and BCL-XL (Fig. 2G). Thus, these data implied that priming with the flo8 mutant blocked $C$. albicans-induced thymus atrophy by prohibiting the apoptosis of $\mathrm{CD}^{+} \mathrm{CD}^{+}, \mathrm{CD}^{+}$, and $\mathrm{CD}^{+}$ T cells. 
A

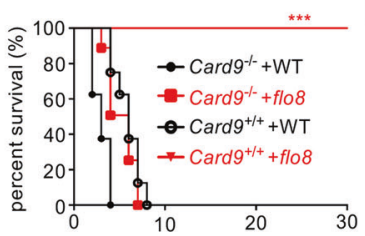

D

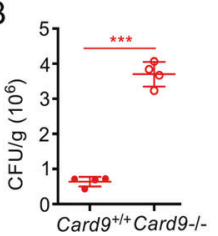

E
C

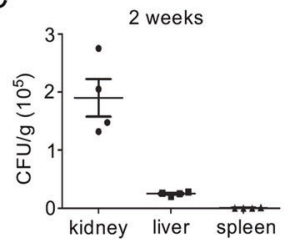

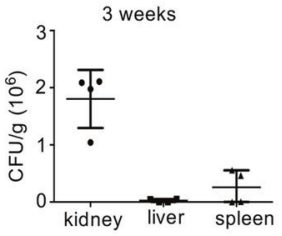

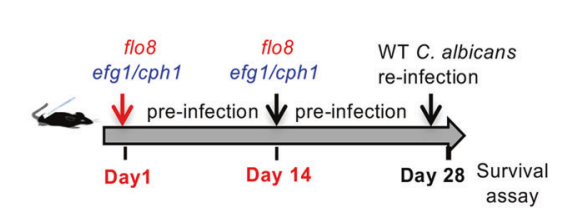

F

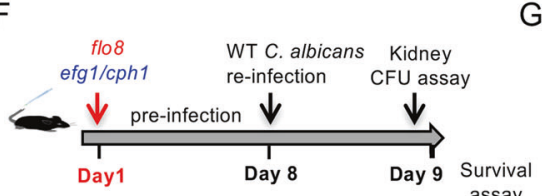

I

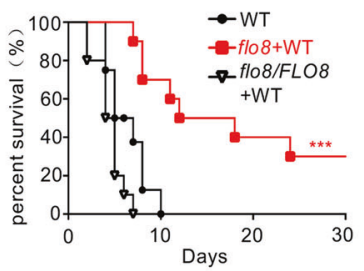

$\mathrm{L}$

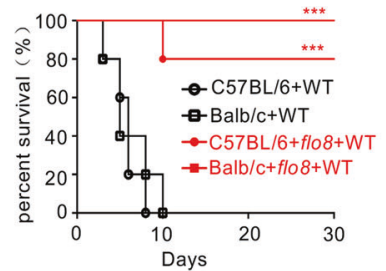

M

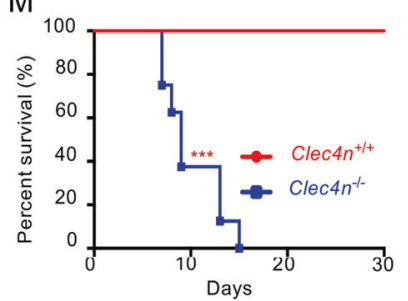

J

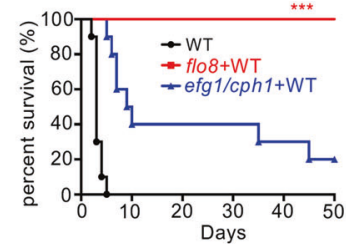

G

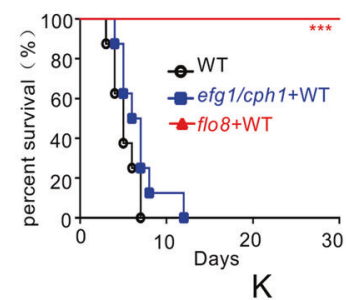

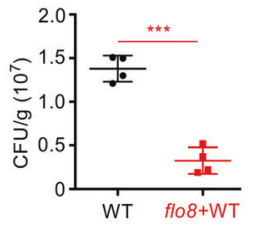

$\mathrm{H}$

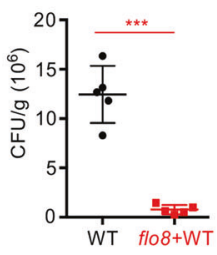

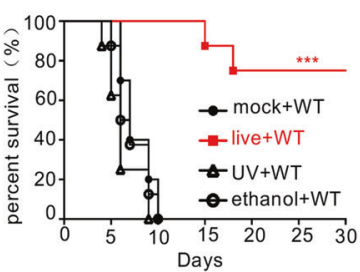
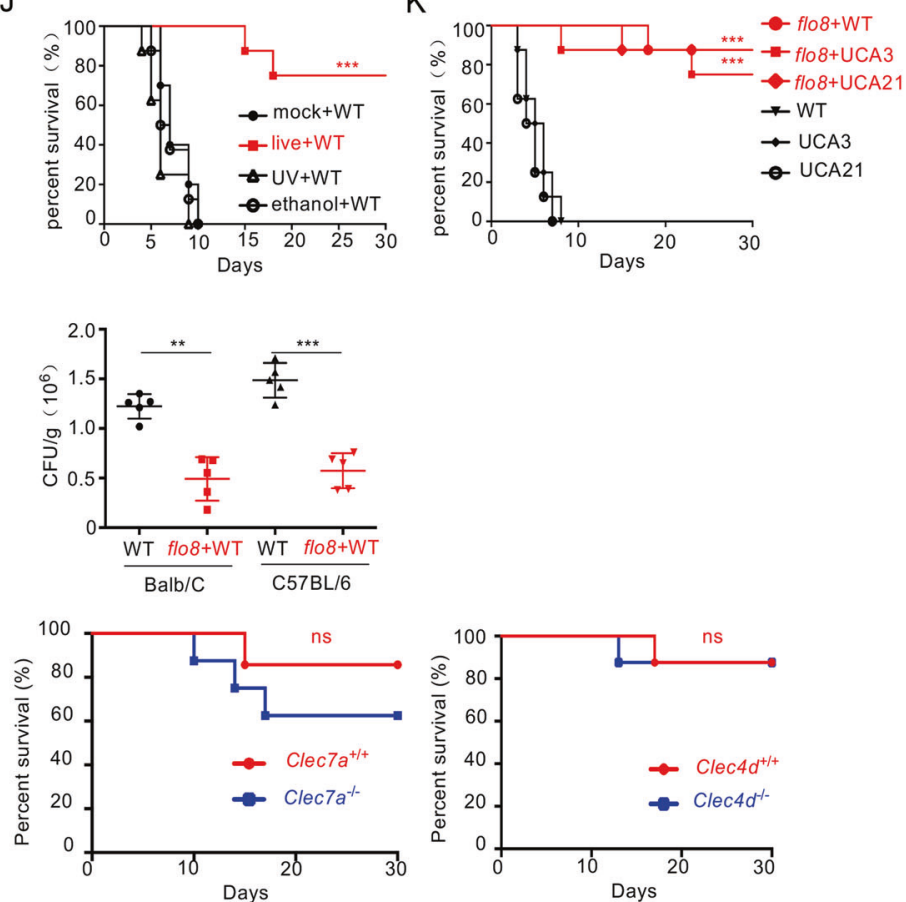

Fig. 1 Live nonhyphal flo8 null mutant primary challenge protects mice from candidiasis depending on Dectin-2. A Survival curves of wildtype $\left(\mathrm{Card}^{+/+}\right)$and Card9-deficient $\left(\mathrm{Card9^{-1- }}\right)$ mice, which were intravenously infected with $5 \times 10^{5}$ CFUs of flo 8 mutant $(n=8)$. B Kidney fungal burden of $\mathrm{Card9}^{-1-}$ mice infected with $5 \times 10^{5} \mathrm{CFUs}$ of flo 8 for $24 \mathrm{~h}(n=4)$. C Kidney fungal burden of mice infected with $5 \times 10^{5} \mathrm{CFUs}$ of flo 8 for 2 or 3 weeks $(n=4)$. D, E Strategy for the primary infection and reinfection. Mice were intravenously infected with live $5 \times 10^{5}$ CFUs of the flo 8 or efg1/cph1 mutant twice at an interval of 14 days and reinfected with $5 \times 10^{5}$ CFUs of WT C. albicans (SC5314) at day 28 (D). The kidney fungal burden $(n=4$, right) was determined at day 30 , and the survival rate $(n=10$, left) was evaluated for another 50 days (E). F-H Strategy for primary infection and reinfection. Mice were intravenously infected with $5 \times 10^{5} \mathrm{CFUs}$ of the live flo 8 or efg $1 / \mathrm{cph} 1 \mathrm{mutant}$ for 7 days and then reinfected with $5 \times 10^{5}$ CFUs of lethal WT C. albicans at day $8(\mathbf{F})$. The survival rate (G) and renal fungal burden (H) of mice were determined $(n=8)$. I Survival curves of C57BL/6 mice that were previously inoculated with the flo8 mutant or FLO8 revertant strain flo8/FLO8 $\left(1 \times 10^{5}\right.$ CFUs) and reinfected with $5 \times 10^{5}$ CFUs of WT C. albicans $(n=8)$. J Survival curves of C57BL/6 mice, which were primary challenged with the live, UV-inactivated or $75 \%$ ethanol-inactivated flo $8\left(5 \times 10^{5}\right.$ CFUs) mutant and then rechallenged with $5 \times 10^{5}$ CFUs of WT C. albicans $(n=8)$. K Survival curves of mice that were previously infected as described in (F) and reinfected with $5 \times 10^{5}$ CFUs of WT C. albicans or the clinical isolate UCA3 or UCA21 $(n=8)$. L Survival curves $(n=10)$ and kidney fungal burdens of C57BL/6 and Balb/C mice, which were primarily infected and reinfected as described in (F). M Survival curves of Clec $4 n^{-/-}$, Clec $7 a^{-1-}$ and Clec $4 e^{-1-}$ mice, which were infected with $5 \times 10^{5}$ CFUs of flo8 for 7 days and reinfected with $5 \times 10^{5}$ CFUs of WT C. albicans $(n=8)$. Bars, mean \pm SEM. ${ }^{*} p<0.05,{ }^{* *} p<0.01$, ${ }^{* * *} p<0.001$, ns not significant, determined by the log rank (Mantel-Cox) test $(\mathbf{A}, \mathbf{E}, \mathbf{G}, \mathbf{I}, \mathbf{J}, \mathbf{K}, \mathbf{L}, \mathbf{M})$ or the unpaired $t$ test $(\mathbf{B}, \mathbf{E}, \mathbf{H}, \mathbf{L})$. Similar results were obtained in at least two independent experiments 

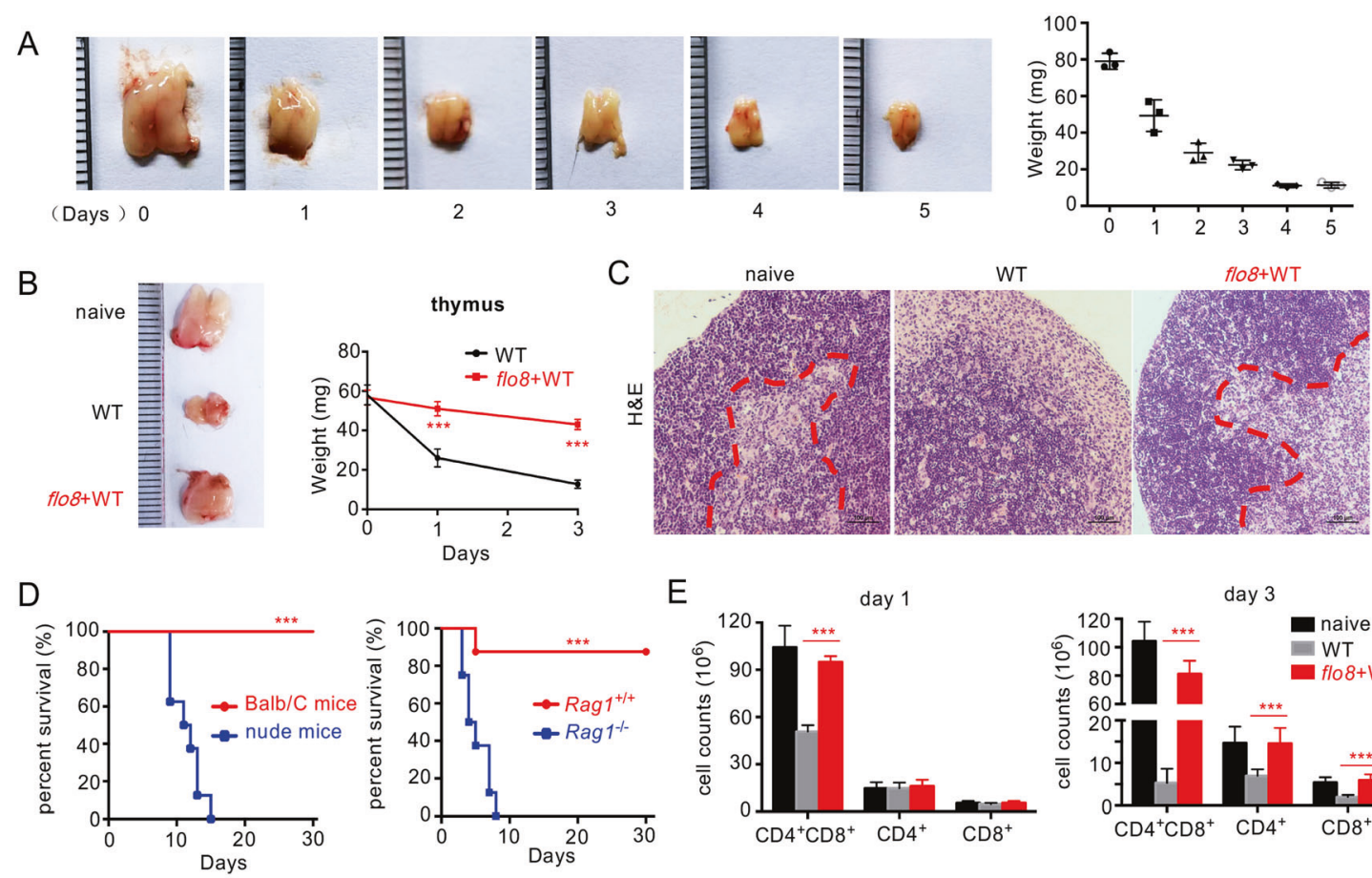

WT

E

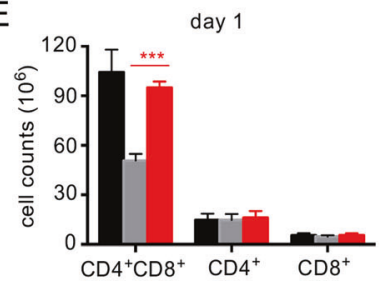

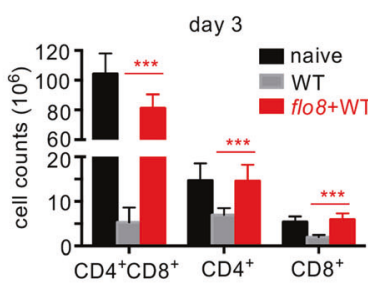

F

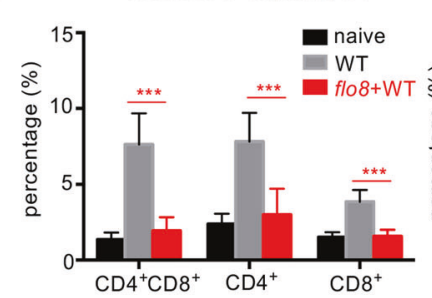

G

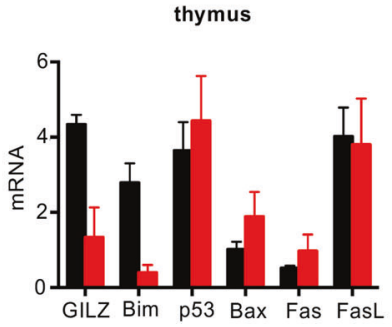

caspase $3^{+}$thymocytes

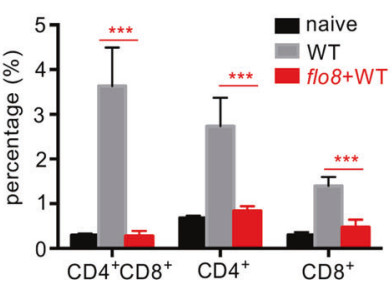

thymus

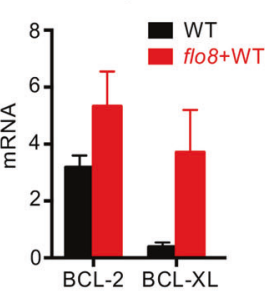

$\mathrm{H}$

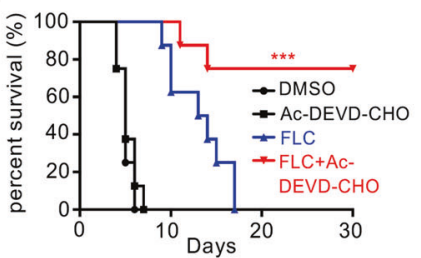

I

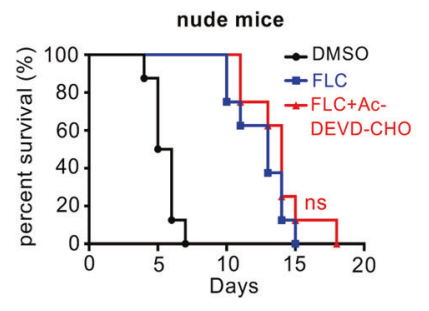

Fig. 2 Thymus atrophy abrogation by prior inoculation with the flo 8 mutant is required for resistance to candidiasis. A Photograph of a representative thymus and thymic weights of mice infected with $5 \times 10^{5}$ CFUs of WT C. albicans for 0-5 days. B Photograph of a representative thymus and thymic weights of mice that were primarily challenged with $5 \times 10^{5}$ CFUs of flo 8 and then rechallenged with $5 \times 10^{5}$ CFUs of WT C. albicans for $24 \mathrm{~h}$. C Histological analysis (H\&E staining) of thymuses from mice treated as described in (B). The dotted red line indicates the division between the cortex and medulla. D Survival curves of nude mice $(n=10)$ and Rag $1^{-1-}$ mice $(n=8)$ infected with $5 \times 10^{5}$ CFUs of the flo8 mutant for 7 days and reinfected with $5 \times 10^{5}$ CFUs of WT C. albicans. E FACS quantification of T cells stained with anti-CD4 and anti-CD8 antibodies in the thymuses of mice infected with $5 \times 10^{5}$ CFUs of the flo8 mutant for 7 days and reinfected with $5 \times 10^{5}$ CFUs of WT C. albicans for 1 or 3 days $(n=5)$. F FACS analysis of Annexin $\mathrm{V}^{+}$cells or Caspase- $3^{+}$apoptotic T cells in thymus organs from mice infected with the $5 \times$ $10^{5}$ CFUs of the flo 8 mutant for 7 days and reinfected with $5 \times 10^{5}$ CFUs of WT C. albicans for 3 days $(n=5)$. G RT-PCR analysis of the expression of proapoptotic genes (GILZ, Bim, p53, Bax, Fas, FasL) and antiapoptotic genes (Bcl-2, BCL-XL) in the thymuses of mice infected with the $5 \times 10^{5}$ CFUs of the flo 8 mutant for 7 days and reinfected with $5 \times 10^{5}$ CFUs of WT C. albicans for 1 day $(n=5)$. Survival curves of Balb/C $(\mathbf{H})$ and nude mice (I) infected with $5 \times 10^{5}$ CFUs of WT C. albicans and treated with drugs once a day for 3 days. Fluconazole (FLC), $0.5 \mathrm{mg} / \mathrm{kg}, \mathrm{Ac}-\mathrm{DEVD}-\mathrm{CHO}$, $10 \mathrm{mg} / \mathrm{kg}(n=8)$. Bars, mean \pm SEM. ${ }^{*} p<0.05,{ }^{* *} p<0.01,{ }^{* * *} p<0.001$, ns not significant, determined by one-way ANOVA (E, F), the log rank (Mantel-Cox) test $(\mathbf{D}, \mathbf{H}, \mathbf{I})$, or the unpaired $t$ test $(\mathbf{B})$. Similar results were obtained in at least two independent experiments

Blockade of infection-induced T-cell apoptosis by a caspase-3 inhibitor has been reported to be highly beneficial in sepsis treatment. ${ }^{23}$ Consistently, we found that treatment with the caspase-3 inhibitor Ac-DEVD-CHO combined with the antifungal agent fluconazole for 3 days significantly improved the survival rate of mice infected with lethal C. albicans (Fig. $2 \mathrm{H}$ ). However, this combination did not improve the survival rate of athymic nude mice (Fig. 2I). These data suggested that inhibiting T-cell apoptosis was decisive for conferring host resistance to $C$. albicans infections. 
Priming with the flo8 mutant maintains the continuous output of naive $T$ cells from the thymus to the spleen

It has been shown that at least half of the peripheral T lymphocytes in the spleen have a 24-48 h life-span, and the renewal of peripheral T cells in the spleen is maintained by the thymic output of mature $\mathrm{T}$ cells. ${ }^{24}$ We confirmed that $C$. albicans infection dramatically decreased the $\mathrm{CD} 4^{+}$and $\mathrm{CD} 8+\mathrm{T}$-cell numbers in the spleen over time (Figs. 3A and S3A). However, priming with the flo8 mutant successfully maintained the numbers of $\mathrm{CD}^{+}$and $\mathrm{CD} 8+$ T cells in the spleens of infected mice (Figs. 3A and S3A). However, this priming failed to inhibit the apoptosis of splenic $\mathrm{CD}^{+}$and CD8 + T cells (Figs. 3B and S3B), suggesting that the maintenance of T-cell numbers in the spleen was not attributable to the inhibition of T-cell apoptosis. Since the maintenance of peripheral T cells in the spleen is supported by thymic output, ${ }^{25}$ we assumed that priming with the flo 8 mutant facilitated the output of naive $T$ cells from the thymus to the spleen. We found that priming with the flo8 mutant increased the expression of splenic T-cell receptor excision circles (TRECs) (Fig. 3C), which are well-established markers for assessing thymic output. ${ }^{26}$ As expected, C. albicans infection significantly decreased the number of naive $T$ cells (defined herein as $\mathrm{CD}^{+} \mathrm{CD}^{2} \mathrm{~L}^{+}$) in the spleen, while priming with the flo8 mutant sustained the number of naive T cells in the spleen (Figs. 3D and S3C). Consequently, priming with the flo 8 mutant significantly increased the number of $C$. albicans-induced IFN- $\gamma^{-}$ producing Th1 cells and the concentrations of IFN- $\gamma$ in the spleen (Figs. 3E, F and S3D). Together, these data indicated that priming with the flo8 mutant facilitated the output of naive T cells from the thymus to the spleen, which enhanced C. albicans-induced Th1mediated antifungal immune responses.

We further depleted CD4+ T cells in mice during priming with the flo8 mutant. We found that intravenous injection of a CD4specific antibody completely blocked the protective roles of flo8 mutant priming against C. albicans infections (Fig. 3G). Moreover, treatment with anti-CD4 in mice infected with C. albicans significantly inhibited thymus weight loss and increased the numbers of $\mathrm{CD}^{+} \mathrm{CD}^{+}$and $\mathrm{CD} 4^{+} \mathrm{T}$ cells in the thymus or $\mathrm{CD} 4{ }^{+} \mathrm{T}$ cells in the spleen induced by flo 8 mutant priming (Fig. $3 \mathrm{H}-J)$. In contrast, this treatment had no influence on the number of $\mathrm{CD} 8+\mathrm{T}$ cells in the thymus or spleen (Fig. $3 \mathrm{H}-\mathrm{J}$ ). However, treatment with anti-CD4 in uninfected mice decreased the number of CD4+ T cells in only the spleen (Fig. 3K). Thus, these data implied that $\mathrm{CD} 4+\mathrm{T}$ cells were essential for the protective benefits induced by the flo 8 mutant against C. albicans infection.

\section{Priming with the flo 8 mutant induces IL-10 secretion in the} thymus to inhibit thymocyte apoptosis

It has been shown that the anti-inflammatory cytokine IL-10 can suppress thymocyte apoptosis partially by upregulating $\mathrm{BCl}-2$ expression. $^{27-29}$ Here, we found that C. albicans infection significantly increased the concentrations of proinflammatory cytokines, including TNF- $a$ and IL-6, in the thymus (Fig. 4A), whereas priming with the flo 8 mutant significantly decreased the concentrations of these cytokines in the secondary challenge with C. albicans (Fig. 4A). However, priming with the flo8 mutant for 6 days induced IL-10 production at a concentration of $\sim 20 \mathrm{ng} / \mathrm{ml}$ in the mouse thymus (Fig. 4B). In contrast, challenge with the C. albicans WT strain or efg1/cph1 mutant for 6 days induced only $\sim 5 \mathrm{ng} / \mathrm{ml} \mathrm{IL-10}$ in the mouse thymus (Fig. S4A). These data suggested that the flo 8 mutant was more potent at inducing IL-10 production in the mouse thymus than the WT or efg $1 / \mathrm{cph} 1$ mutant. However, no significant changes in IL-10 production were observed in the spleens of the infected mice (Figs. 4B and S4A). To determine whether the thymus protection induced by flo 8 mutant priming was dependent on IL-10, we blocked the function of the IL-10 receptor (IL-10R) using its specific antibody. Blockade of IL$10 R$ significantly impaired the protection induced by flo 8 mutant priming, as determined by a lower survival rate, higher kidney fungal load, and more thymus weight loss during C. albicans infection (Fig. 4C, D). Moreover, blocking IL-10R significantly reduced the survival of mice infected with the $C$. albicans WT strain (Fig. S4B), suggesting that the IL-10/IL-10R axis is required for host immune defenses against $C$. albicans infections. Furthermore, this blockade completely inhibited the increases in thymic $\mathrm{CD}^{+} \mathrm{CD}^{+}{ }^{+}, \mathrm{CD}^{+}{ }^{+}$, and $\mathrm{CD} 8^{+}{ }^{-}$-cell numbers and the frequency of thymic $T$ cells expressing Annexin $\mathrm{V}$ induced by flo 8 mutant priming (Figs. 4E, F and S4C, D). However, this blockade had no influence on the frequency of splenic CD4+ T and CD8+ T cells expressing Annexin V (Figs. 4F and S4D). Consistently, blockade of IL-10R completely impaired the flo8 mutant-induced suppression of the downregulation of the apoptotic genes GILZ and Bim and the upregulation of the antiapoptotic genes $\mathrm{Bcl} 2$ and $\mathrm{BCL}-\mathrm{XL}$ in the thymus (Fig. S4E). Consequently, this blockade also impaired the flo 8 mutant-induced upregulation of TREC expression and the increase in naive T-cell numbers in the spleen during $C$. albicans infection (Fig. 4G, H). Collectively, these data indicated that priming with the flo8 mutant-induced IL-10 secretion in the thymus to inhibit thymocyte apoptosis and thus confer host protection against $C$. albicans infection.

Furthermore, a low dose of recombinant IL-10 (rlL-10, $1 \mu \mathrm{g} /$ mouse) significantly decreased the kidney fungal burden in mice infected with WT strains (Fig. S4F). The medium dose of rlL-10 (5 $\mu \mathrm{g} /$ mouse) had no influence on the kidney fungal burden in infected mice (Fig. S4F). However, a high dose of rlL-10 $(5 \mu \mathrm{g} /$ mouse) significantly increased the fungal burden in the kidneys of infected mice (Fig. S4F). Different doses of recombinant IL-10 are known to have differential influences on the survival of mice with sepsis. $^{30,31}$

Mannans on the surface of the serum-induced flo 8 mutant stimulate macrophages and DCs to produce IL-10

To explore the source of IL-10 production after priming with the flo8 mutant, thymocytes from mice primed for 6 days were subjected to immunocytochemical staining to determine the IL10 -producing cells. Thymocytes from mice primed with the flo 8 mutant had a greater frequency of IL-10-producing DCs (defined herein as live CD11 $\mathrm{c}^{+} \mathrm{IL}-10^{+}$cells) and macrophages (defined here as live $\mathrm{CD} 11 \mathrm{~b}^{+} \mathrm{IL}-10^{+}$cells) than unprimed mice (Fig. 5A). However, infections with flo8, efg1/cph1, and low-dose WT C. albicans slightly increased the percentage of Treg (defined herein as live $\mathrm{CD}^{+}{ }^{+} \mathrm{Foxp}^{+}$) cells in the mouse spleen but had no influence on thymic Treg differentiation (Fig. S5A). Consequently, the frequency of IL-10-producing Treg cells in the thymus organs of mice infected with flo8, efg1/cph1, or WT C. albicans was low (Fig. S5B)

A direct in vitro assay revealed that the serum-induced flo8 mutant (flo8-I) could stimulate higher levels of IL-10 production than the yeast flo8 mutant (flo8-Y) or efg1/cph1 mutant in BMDCs and BMDMs (Fig. 5B). Furthermore, the deficiency of either Dectin-2 or CARD9, but not Dectin-1 or Dectin-3, completely impaired IL-10 production in BMDCs after stimulation with a serum-induced flo8 mutant (flo8-FI) (Fig. 5C). Thus, these data implied that serum stimulation might increase the exposure of mannans on the surface of the flo 8 mutant to induce Dectin-2/CARD9-mediated IL-10 production in macrophages and DCs.

It has been shown that the structure and content of mannans in C. albicans are dynamically altered during dimorphic transition in response to serum induction. ${ }^{32,33}$ We explored the surface quantity of mannans with ConA staining in the flo 8 or efg $1 / \mathrm{cph} 1$ mutant with or without serum treatment, and the resulting cells were assayed by flow cytometry as described previously. ${ }^{34}$ As expected, more mannans were exposed on the surface of the serum-induced flos mutant than on those of the flo8 and serum-induced efg1/cph1 mutants (Fig. 5D). 
A

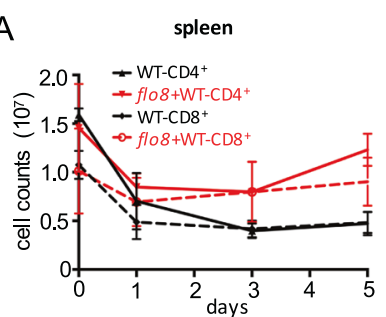

D
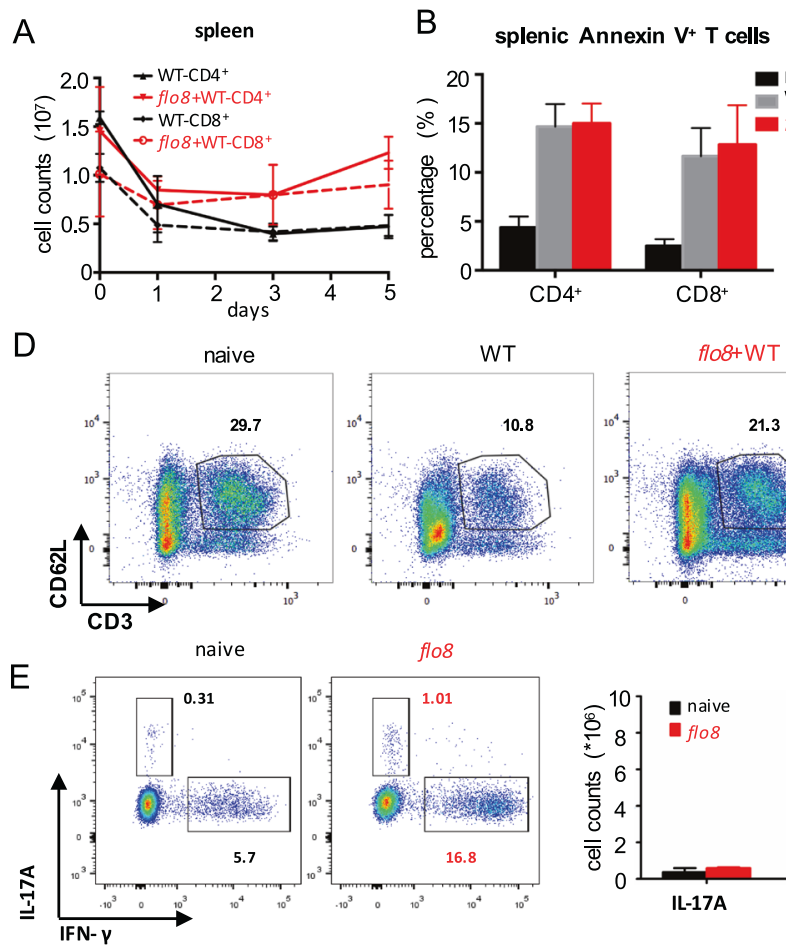

WT

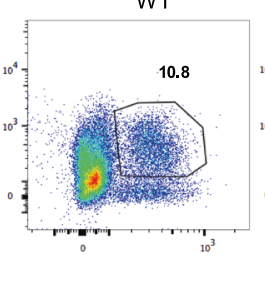

G

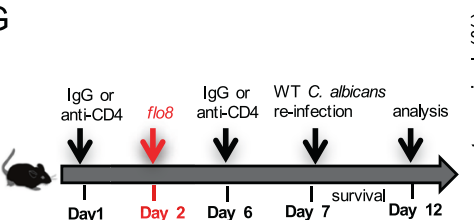

I
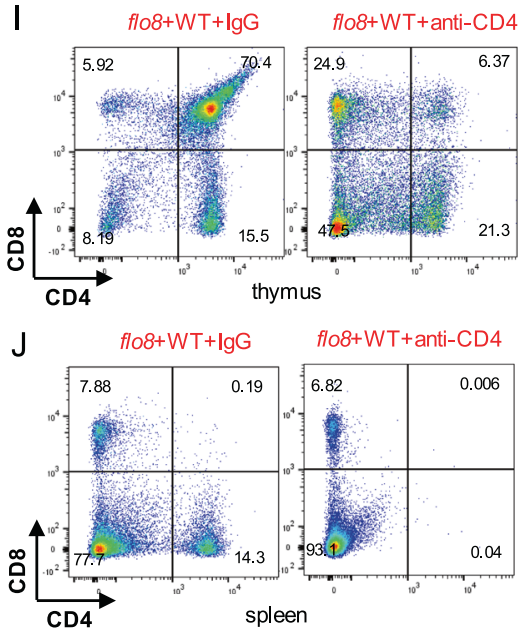
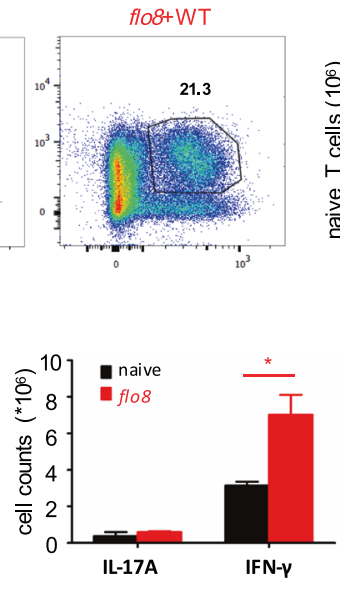

C

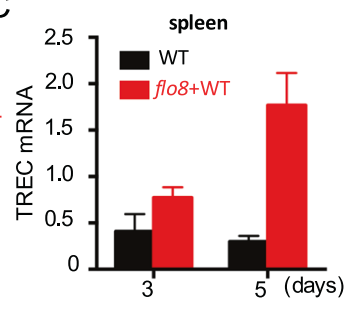

spleen
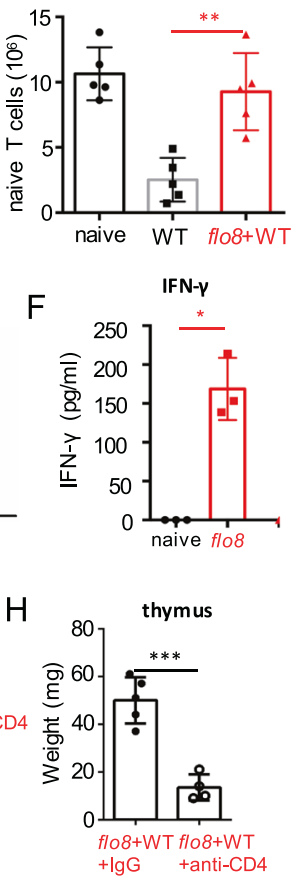

$\mathrm{K}$
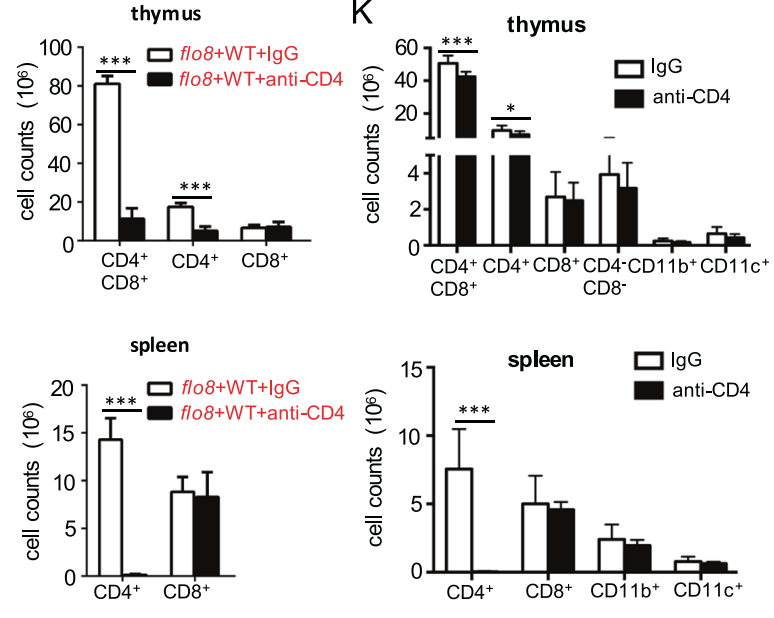

Fig. 3 Prior inoculation with the flo8 mutant promoted naive T-cell supplementation and Th1 differentiation. A-C Mice were first inoculated with $5 \times 10^{5}$ CFUs of the flo 8 mutant and reinfected with $5 \times 10^{5}$ CFUs of WT C. albicans for $3(\mathbf{A}, \mathbf{B})$ or 5 (C) days $(n=5)$. Flow cytometry was used to analyze the number of $\mathrm{CD} 4^{+}$and $\mathrm{CD} 8^{+}$T cells $(\mathbf{A})$ and the percentages of apoptotic CD4 $4^{+}$and $\mathrm{CD} 8^{+} \mathrm{T}$ cells $(\mathbf{B})$ in the spleen. RT-PCR was used to determine the expression of the T-cell receptor rearrangement excision circle (TREC) gene in the spleen (C). D FACS analysis of naive T cells $\left(\mathrm{CD}^{+}{ }^{+} \mathrm{CD} 62 \mathrm{~L}^{+} \mathrm{T}\right.$ cells) in the spleens of mice that were previously infected with the flo8 mutant or not and reinfected with $5 \times 10^{5}$ CFUs of WT C. albicans for 5 days. E FACS analysis of Th1 and Th17 cells in the spleen. The counts of CD4 ${ }^{+}$IL$17 \mathrm{~A}^{+}$and $\mathrm{CD} 4^{+} \mathrm{IFN}-\gamma^{+}$T cells are shown in the right panel. F ELISA results for the detection of cytokine IFN- $\gamma$ secretion from splenic cells of mice that were previously inoculated with flo8 for 7 days or not. G-J Strategy (left) for treating mice with anti-mouse CD4 antibodies. The survival curves (right) of mice that were injected i.p. with $250 \mu \mathrm{g}$ of anti-CD4 antibodies prior to infection with $5 \times 10^{5}$ CFUs of the flo8 mutant and reinfection with $5 \times 10^{5}$ CFUs of WT C. albicans $(n=8)$. The thymic weights of the mice were recorded $(\mathbf{H})$, and the percentages and numbers of thymic (I), and splenic (J) T cells were analyzed by flow cytometry. K FACS analysis of immune cells in the thymuses and spleens from mice that were treated with $250 \mu \mathrm{g}$ of anti-mouse CD4 antibodies or with IgG alone for 7 days. Bars, mean \pm SEM. ${ }^{*} p<0.05$, ${ }^{* *} p<0.01,{ }^{* * *} p<0.001$, ns not significant, determined by the unpaired $t$ test $(\mathbf{B}, \mathbf{D}, \mathbf{E}, \mathbf{F}, \mathbf{H}, \mathbf{I}, \mathbf{J}, \mathbf{K})$. Similar results were obtained in at least two independent experiments 
A

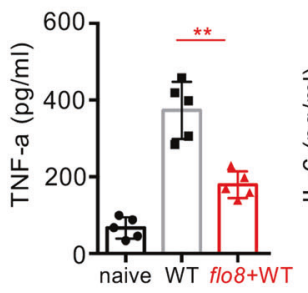

C

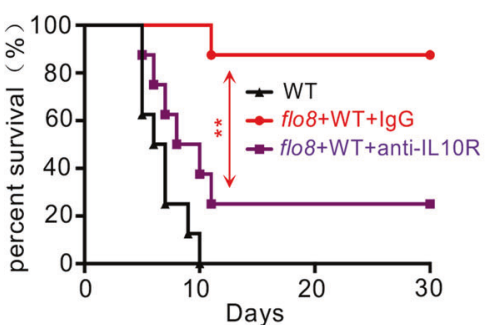

thymus
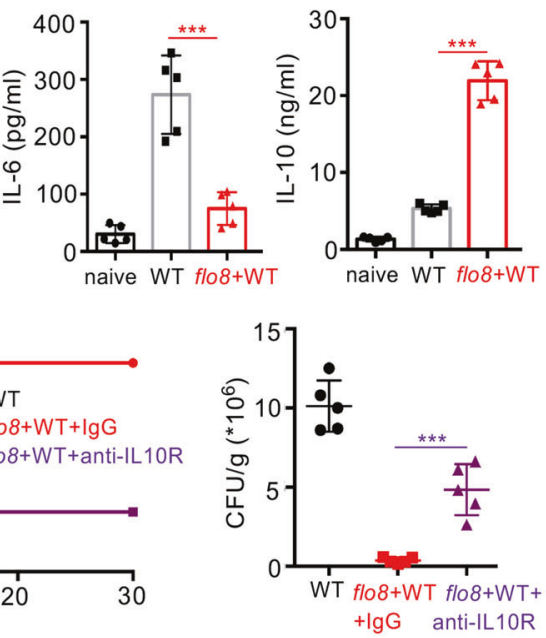

B
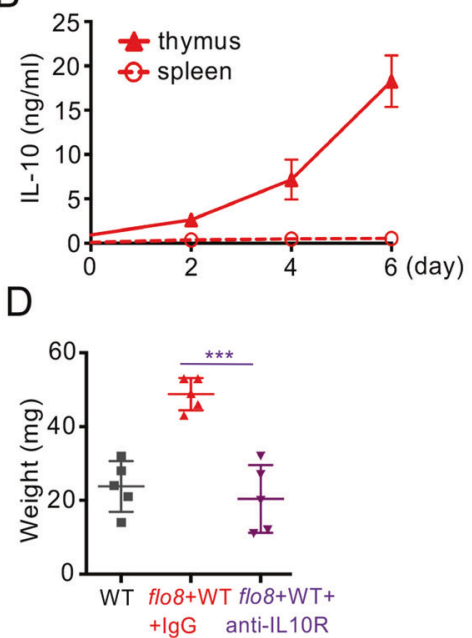

E CD4 $^{+}{ }^{+} D 8^{+}$thymocytes

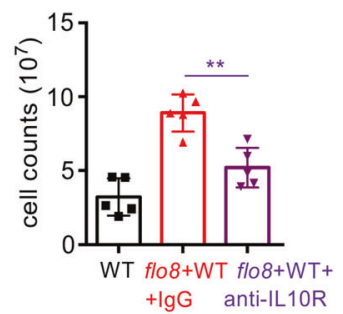

$\mathrm{F}$

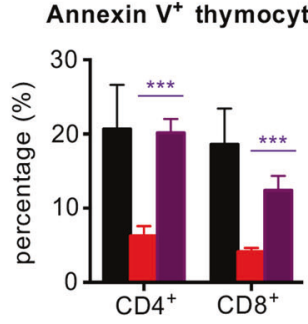

Annexin $\mathrm{V}^{+}$

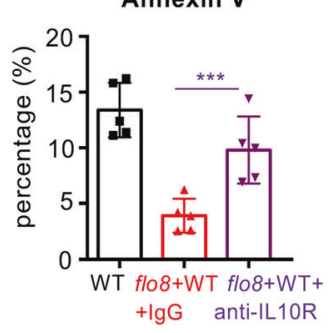

Caspase $3^{+}$

thymus
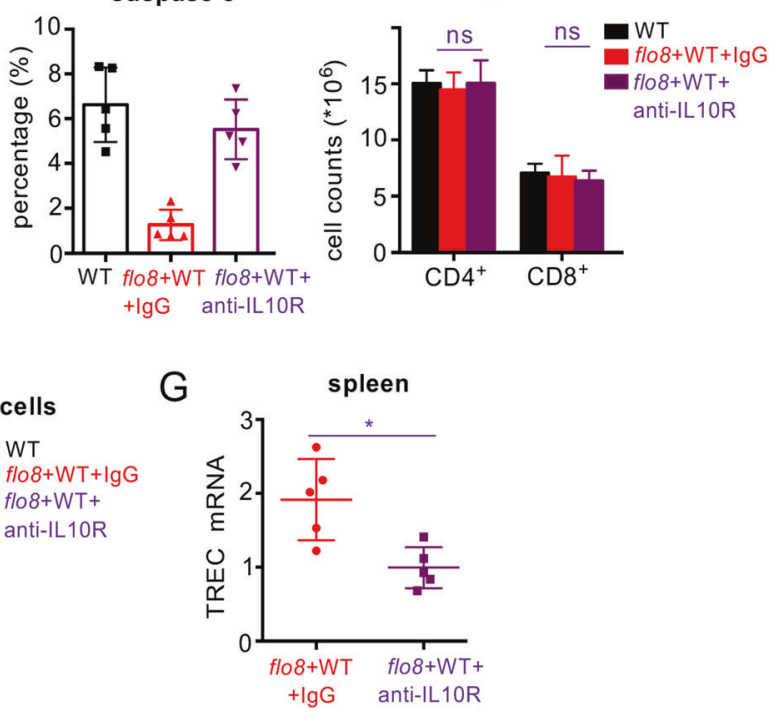

$\mathrm{H}$
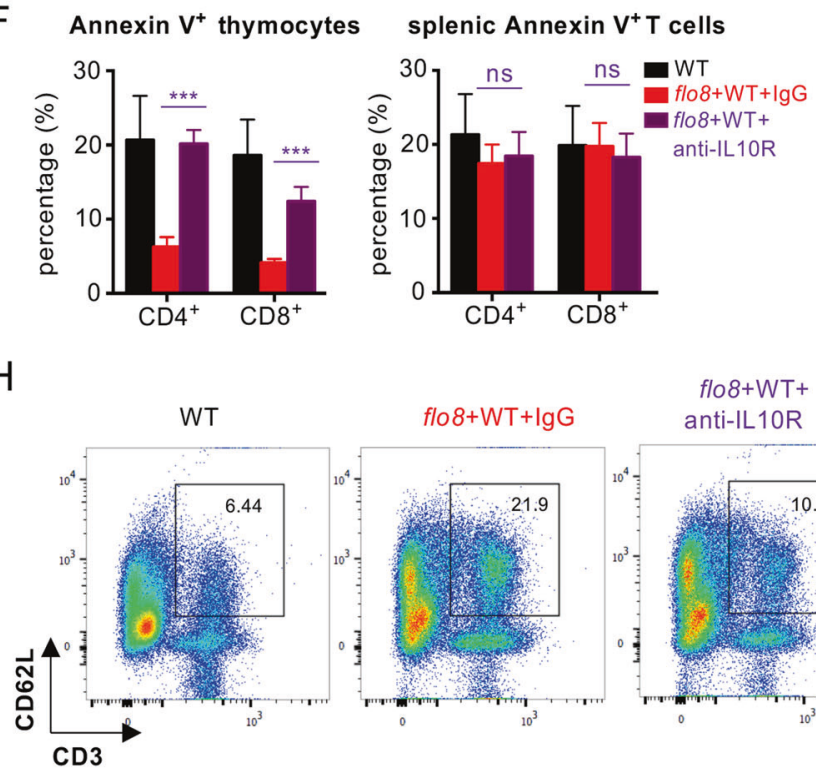

flo8+WT+ anti-IL10R
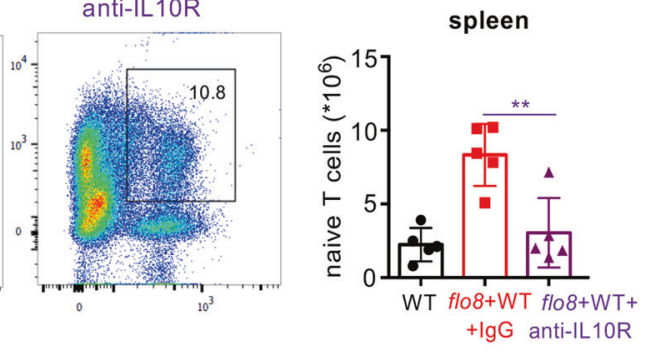

Fig. 4 Prevention of thymus atrophy by flo8 mutant priming was dependent on IL-10 in vivo. A ELISA results for the detection of cytokines TNF $\alpha$, IL-6, and IL-10 in the thymus organs of mice primarily infected with $5 \times 10^{5}$ CFUs of the flo 8 mutant and reinfected with $5 \times 10^{5}$ CFUs of WT C. albicans for $24 \mathrm{~h}$. B ELISA results of the detection of IL-10 in the thymus and spleen organs of mice infected with $5 \times 10^{5}$ CFUs of the flo 8 mutant for 0-6 days $(n=5)$. C-H Mice were infected with $5 \times 10^{5}$ CFUs of the flo 8 mutant for 7 days and reinfected with $5 \times 10^{5}$ CFUs of WT C. albicans. PBS, rabbit lgG (300 $\mu \mathrm{g} /$ mouse) or an anti-IL10R antibody ( $300 \mu \mathrm{g} / \mathrm{mouse})$ was injected intraperitoneally on days $1,3,5,7$, and 9 . The survival rates and renal fungal burdens of mice were determined (C). The weights of the thymus were recorded (D). The numbers of thymic T cells and percentages of Annexin $\mathrm{V}^{+}$and caspase ${ }^{+}$subpopulations gated in $\mathrm{CD} 4^{+} \mathrm{CD} 8^{+} \mathrm{T}$ cells $(\mathbf{E})$ and the percentages of apoptotic $\mathrm{CD}^{+}$and $\mathrm{CD}^{+} \mathrm{T}$ cells in the thymus and spleen (F) were analyzed by flow cytometry. The expression of the T-cell receptor rearrangement excision circle (TREC) in the spleen (G) was analyzed by RT-PCR. Naive T cells in the spleen were analyzed by flow cytometry $(\mathbf{H})$. Bars, mean \pm SEM. ${ }^{*} p<0.05,{ }^{* *} p<0.01,{ }^{* * *} p<0.001$, ns not significant, determined by the log rank (Mantel-Cox) test (C) and the unpaired $t$ test $(\mathbf{A}, \mathbf{C}, \mathbf{D}, \mathbf{E}, \mathbf{G}$, $\mathbf{H}, \mathbf{I})$. Similar results were obtained in at least two independent experiments 
Furthermore, the quantity of surface mannans in the flo8 mutant was increased by serum treatment in a time-dependent manner (Fig. 5E). Consistently, the increase in IL-10 production in BMDMs induced by the flo 8 mutant also corresponded to the serum treatment time (Fig. 5E). Moreover, treatment of the seruminduced flo8 mutant with sodium hydrate successfully removed surface mannans and blocked IL-10 production in BMDMs (Fig. 5F). However, hydrochloric acid treatment had a slight influence on surface mannans in the serum-induced flo 8 mutant and on IL-10 production in BMDCs (Fig. 5F). Thus, these data implied that serum stimulation increased the exposure of mannans on the surface of the flo 8 mutant to induce IL-10 production in macrophages and DCs.

To further confirm our above conclusion, we extracted polysaccharides from the surfaces of WT, efg1/cph1, and flo 8 mutants with or without serum induction and then performed hydrolysis reactions to convert the polysaccharides to monosaccharides for GC-MS analysis. Monosaccharide composition analysis showed that the polysaccharides from the flo8 mutant (fYM) and serum-induced flo8 mutant (fIM) contained mainly mannose (Fig. 5G), indicating that the extracted polysaccharides primarily comprised mannans. As expected, the mannans extracted from the serum-induced flo8 mutant (fIM) were more potent than those extracted from the WT (WYM and WIM), efg1/ cph1 (eYM and elM), and flo8 mutant (fYM) to induce IL-10 production by BMDMs or BMDCs in a dose-dependent manner (Figs. $5 \mathrm{H}$ and $\mathrm{S} 5 \mathrm{C}$ ). Deficiency of either Dectin-2 or CARD9 completely impaired IL-10 production in BMDCs after stimulation with fIM (Fig. 5I). Collectively, these data confirmed that serum stimulation increased the exposure of mannans on the surface of the flo 8 mutant to induce Dectin-2/CARD9-mediated IL-10 production in macrophages and DCs.

Priming with mannans extracted from the flo 8 mutant elicits protective immunity against $C$. albicans infection

We further explored whether mannans extracted from WT strains (WYM vs. WIM) and flo8 mutants with or without serum induction (fIM vs. fYM) elicited immunoprotection against $C$. albicans infection. We observed that priming with fIM potently elicited immunoprotection against $C$. albicans infection compared with that achieved by priming with FYM, WYM, or WIM, as determined by a higher survival rate, lower kidney fungal load, and less thymus weight loss (Fig. 6A, B). Furthermore, priming with fIM or fYM significantly increased the concentrations of IL-10 in the thymus organs of mice infected with $C$. albicans (Fig. 6C). Priming with fIM or fYM successfully maintained the number of CD4+ CD8 $+\mathrm{T}$ cells and significantly decreased the frequency of Annexin $\mathrm{V}$ and caspase- 3 expression in CD4+ CD8 + T cells in the thymuses of mice infected with $C$. albicans (Figs. 6D, $E$ and S6A). Consequently, priming with fIM or fYM sustained the number of naive $\mathrm{T}$ cells (defined herein as $\mathrm{CD}^{+}{ }^{+} \mathrm{CD}_{2} \mathrm{~L}^{+}$) in the spleens of mice infected with C. albicans (Fig. 6F). Collectively, these data suggest that mannans extracted from the flo 8 mutant could induce IL-10 production to inhibit C. albicans-induced thymus atrophy by blocking the apoptosis of immature CD4+ CD8+ T cells.

Priming with the flo8 mutant induces protective immunity against polymicrobial sepsis

To explore whether priming with the flo 8 mutant had protective effects against lethal polymicrobial infections, we performed cecal ligation and perforation (CLP) to construct a mouse model of sepsis as described previously. ${ }^{35}$ Interestingly, priming with the flo8 mutant for a 28-day interval resulted in increased survival and a decreased bacterial burden in the blood and peritoneal cavities of CLP-induced septic mice (Fig. 7A, B). Consistently, this priming significantly reduced CLP-induced tissue lesions, with thinner alveolar septa and less inflammatory cell infiltration than those in control mice (Fig. 7C). In addition, priming with the flo8 mutant for a 7-day interval also significantly protected mice from CLPinduced sepsis, as shown by increased survival and a decreased bacterial burden in the blood and peritoneal cavity (Fig. 7D, E). However, this priming provided no protection for LPS-induced septic mice, which may have been due to the higher levels of proinflammatory cytokines induced by both the flo8 mutant and LPS in mice (Fig. S7A-C). We further primed athymic nude mice and RAG1-deficient mice with CLP-induced sepsis. Priming with the flo8 mutant provided no protection against lethal CLP-induced sepsis in RAG1-deficient or nude mice (Fig. S7D-G). These data indicate that the thymus is essential for protective responses induced by the flo8 mutant against lethal polymicrobial infections.

We further explored whether Th1-mediated responses were essential for flo8 mutant-induced protection against polymicrobial infections. We found that intravenous injection of a CD4- or IFN- $\gamma$-specific antibody completely blocked the protective effects of flo 8 mutant priming against CLP-induced sepsis, as shown by lower survival rates and increased bacterial burdens in the blood and peritoneal cavity compared with those of primed mice receiving control IgG (Fig. 7F-I). Moreover, neutralization of IFN- $\gamma$ in primed mice with CLP-induced sepsis significantly aggravated lung tissue damage (Fig. 7J). Thus, these data indicated that the Th1-mediated responses induced by flo 8 mutant priming were critical for immunoprotection against lethal polymicrobial infections.

\section{DISCUSSION}

The relationship between virulence and morphological transformation is the key issue in studying the pathogenicity of C. albicans. ${ }^{10,36}$ In this study, we identified FLO8 as a potential immunotherapeutic target against systemic C. albicans infection. The disruption of FLO8 in C. albicans could inhibit the yeast-tohyphae transition and elicit protective immune responses against systemic candidiasis in a murine model. Furthermore, the immune protection induced by the flo 8 null mutant is not the commonality of all hyphae-deficient strains since the efg $1 / \mathrm{cph} 1$ null mutant kept in yeast form provided no immunoprotection against subsequent lethal C. albicans infection. However, a genetically engineered C. albicans tet-NRG1 strain, which is conditionally kept in yeast form in vivo, can evoke a protective immune response against subsequent lethal C. albicans infection. ${ }^{37}$ The $C$. albicans strain PCA-2, which is incapable of yeast-to-hyphae conversion, confers protection against subsequent challenge with a highly pathogenic C. albicans strain. ${ }^{38,39}$ However, the yeast cell-associated molecules that trigger protective immune responses remain unclear. During the course of $C$. albicans infection, the initial response of the innate immune system is determined by the recognition of fungal cell wall components, including glucans and mannans. ${ }^{4,41} \mathrm{~A}$ recent study showed that fungus-derived mannans, but not glucan-containing curdlan and zymosan, mediate the protective benefits of commensal fungi. ${ }^{6}$ In our study, we showed that mannans extracted from serum-induced flo 8 mutants could elicit immunoprotection against subsequent lethal $C$. albicans infection. In contrast, mannans extracted from the flo8 mutant had a slight immunoprotective effect. Therefore, mannans exposed on seruminduced flo 8 mutant cells may be critical for evoking protective immune responses against invasive candidiasis or candidemia in a murine model, and serum induction may facilitate mannan modification, which is negatively regulated by $F L O 8$ in C. albicans. ${ }^{33}$ Further studies are needed to clarify the structural alterations of mannans induced by serum in flo 8 mutants.

Immunological studies on infectious diseases have focused mainly on the effector immune response, changes in the blood and peripheral lymphoid organs of infected individuals, and vaccine development. ${ }^{42,43}$ Studies on the thymus in infected individuals have been neglected despite that the thymus is a 
A

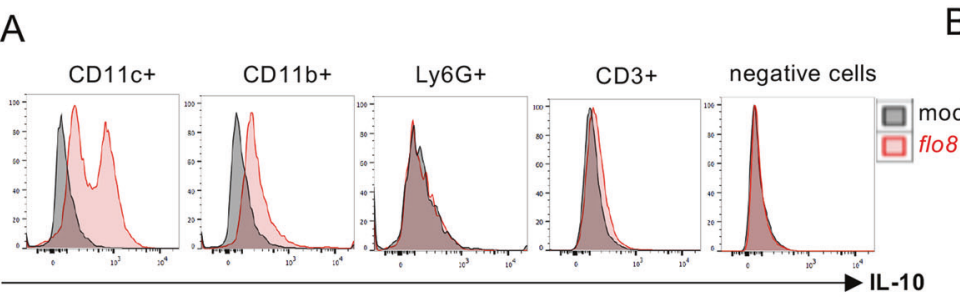

B
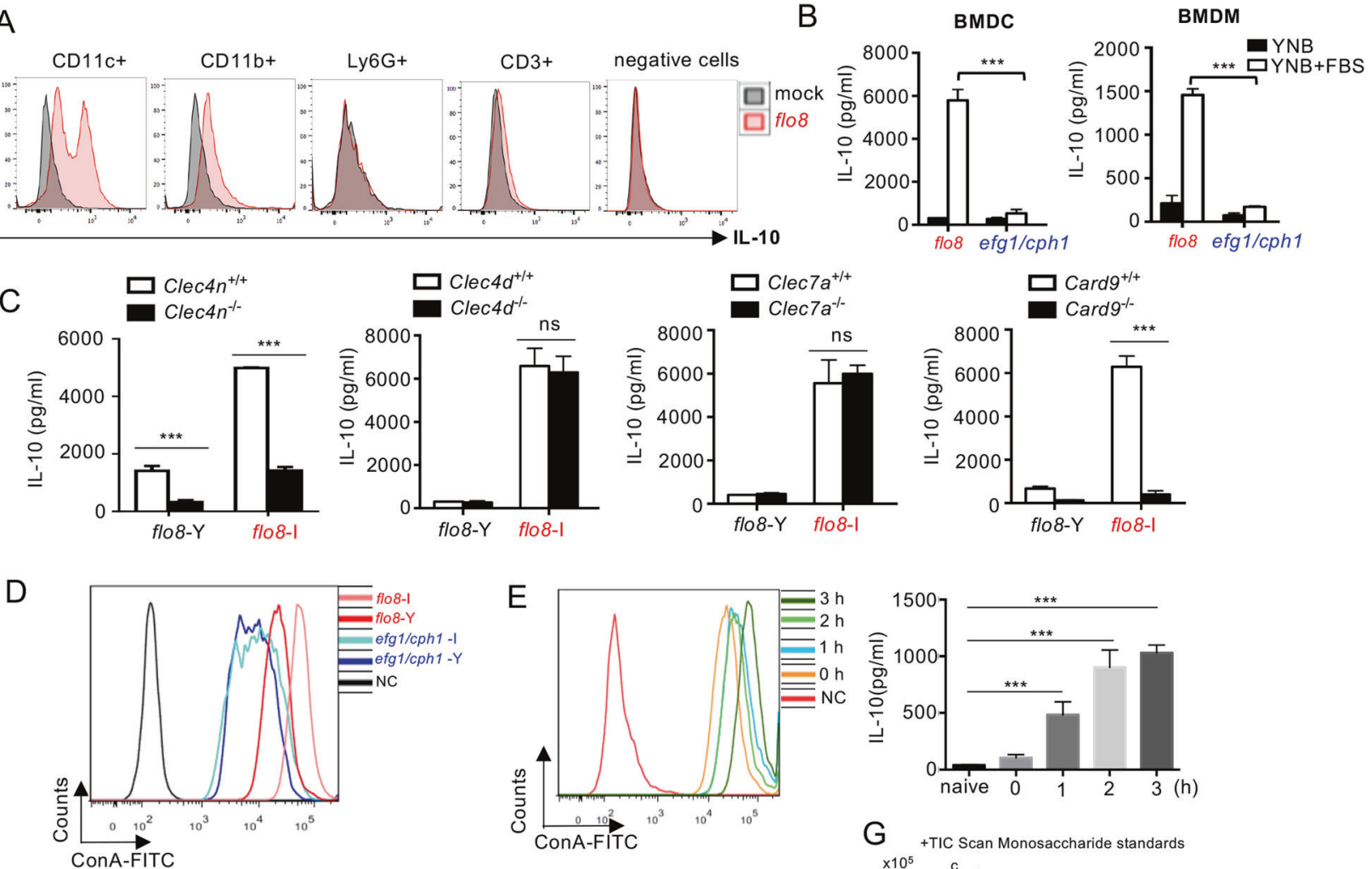

$\mathrm{F}$
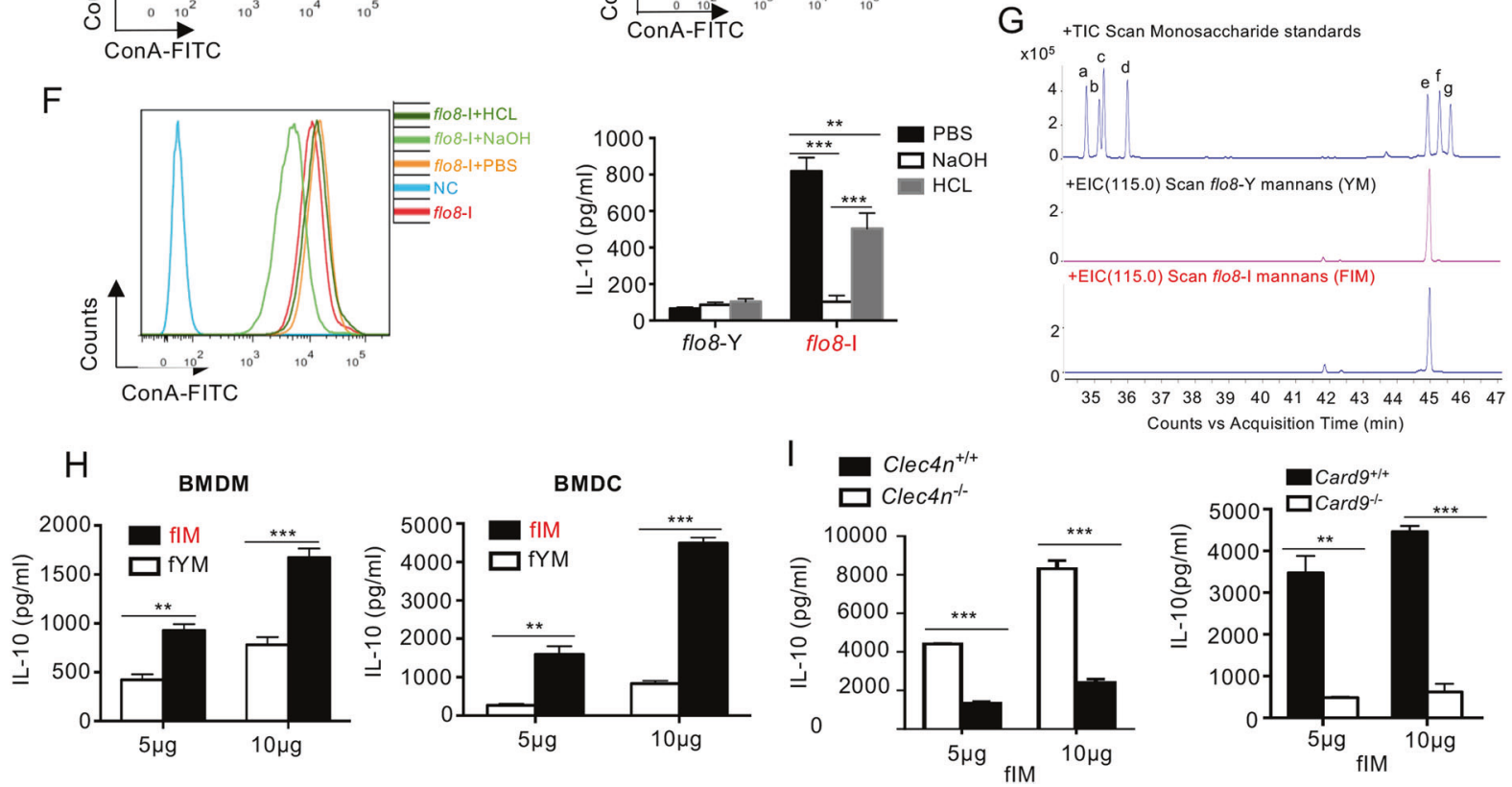

Fig. 5 Mannans extracted from the serum-induced flo8 mutant-induced high levels of IL-10. A Intracellular IL-10 staining of cells in thymus organs from mice that were previously inoculated with $5 \times 10^{5}$ CFUs of the flo 8 mutant for 7 days. B ELISA results of the detection of IL-10 in BMDMs and BMDCs stimulated with the C. albicans flo8 or efg $1 / \mathrm{cph} 1$ mutant and cultured in YNB at $30^{\circ} \mathrm{C}$ or induced with YNB $+10 \%$ FBS at $37^{\circ} \mathrm{C}$ for $3 \mathrm{~h}$ in $5 \% \mathrm{CO}_{2}$. C ELISA results of the detection of IL-10 in wild-type, Clec $4 n^{-1-}$, Clec $4 d^{-1-}, \mathrm{Clec} \mathrm{a}^{-1-}$, and Card $9^{-1-} \mathrm{BMDCs}$ stimulated with the C. albicans flo 8 mutant and cultured in YNB at $30^{\circ} \mathrm{C}($ flo $8-\mathrm{Y})$ or induced with YNB $+10 \% \mathrm{FBS}+5 \% \mathrm{CO}_{2}$ at $37^{\circ} \mathrm{C}$ for $3 \mathrm{~h}($ flo8-I). D FACS quantification of mannans in flo8 and efg $1 / \mathrm{cph} 1$ mutants cultured in $\mathrm{YNB}$ at $30^{\circ} \mathrm{C}(\mathrm{Y})$ or induced with $\mathrm{YNB}+10 \% \mathrm{FBS}$ at $37^{\circ} \mathrm{C}$ for $3 \mathrm{~h}$ in $5 \% \mathrm{CO} 2$ (flo8-I). E FACS quantification of mannans (left) in the flo8 mutant induced with YNB $+10 \% \mathrm{FBS}$ for $0,1,2$, or $3 \mathrm{~h}$ at $37^{\circ} \mathrm{C}$ in $5 \%$ CO, ELISA results of the detection of IL-10 (right) in BMDMs stimulated with the flo8 mutant induced for $0,1,2$, or $3 \mathrm{~h}(\mathrm{MOI}=5)$ for $16 \mathrm{~h}$. F FACS quantification of mannans in the serum-induced flo8 mutant treated with acid or alkali (left). The flo8 mutants were induced with YNB $+10 \%$ FBS at $37^{\circ} \mathrm{C}$ for $3 \mathrm{~h}$ in $5 \% \mathrm{CO}_{2}$ (flo8-I) and heated in PBS, $100 \mathrm{mM} \mathrm{HCl}$ or $2 \%(\mathrm{~m} / \mathrm{v}) \mathrm{NaOH}$ at $95^{\circ} \mathrm{C}$ for $15 \mathrm{~min}$. ELISA results of the detection of IL10 (right) in BMDMs stimulated by the flo8-I mutant treated with acid or alkali for $16 \mathrm{~h}(\mathrm{MOI}=5)$. G Monosaccharide composition analysis of mannans extracted from the flo8 mutant by GC-MS: monosaccharide standards, a, rhamnose; b, fucose; c, arabinose; d, xylose; e, mannose; f, glucose; g, galactose. H ELISA results of the detection of IL-10 in BMDMs and BMDCs stimulated with mannans extracted from the flo8 yeast mutant (fYM) and serum-induced flo 8 mutant (fIM). I ELISA results of the detection of IL-10 in Clec $4 n^{-1-}$ and Card9 ${ }^{-1-}$ BMDCs stimulated by fIM. Bars, mean \pm SEM. ${ }^{*} p<0.05,{ }^{* *} p<0.01,{ }^{* * *} p<0.001$, ns not significant, determined by the unpaired $t$ test (B, C, E, H, I) or one-way ANOVA (F). Similar reults were obtained in at least two independent experiments 
A

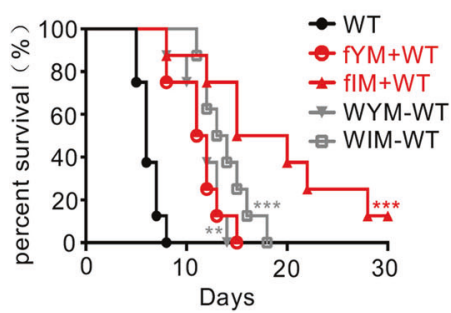

D $\mathrm{CD} 4^{+} \mathrm{CD} 8^{+}$thymocytes

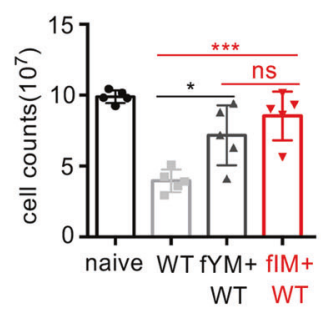

B

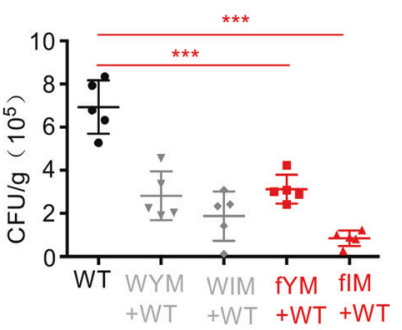

C

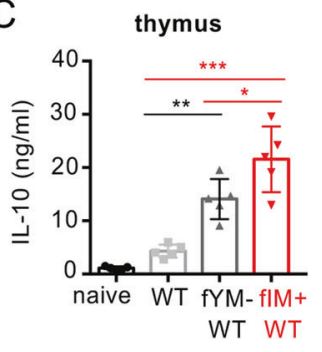

$\mathrm{F}$

naive

$\mathrm{CD}^{+}{ }^{\text {or }} \mathrm{CD} 8^{+}$thymocytes

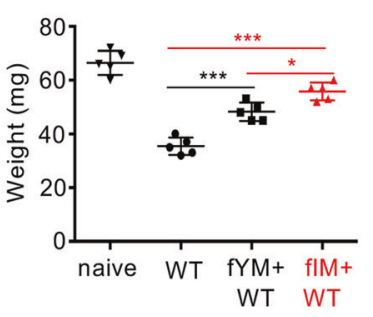

$E$
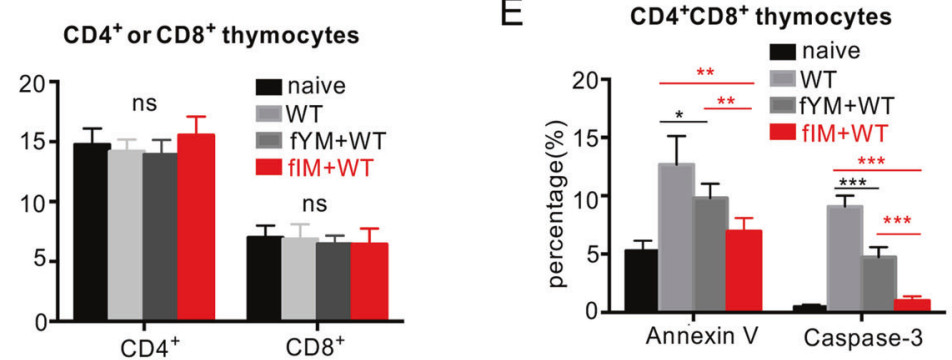

$\mathrm{flM}+\mathrm{WT}$

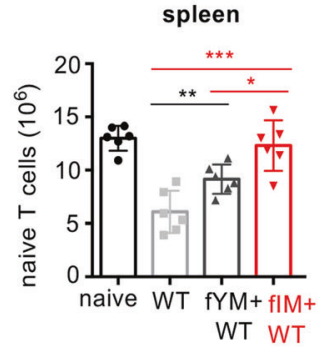

Fig. 6 Mannans extracted from the serum-induced flo8 mutant exert protective effects. A Survival curves and renal fungal burdens of mice injected with different mannans extracted from yeast flo8 mutant (fYM), yeast WT strains (WYM), serum-induced flo8 mutant (fIM), and seruminduced WT (WIM) strains. B-F C57BL/6 mice were injected i.p. with PBS or fYM, fIM WYM, WIM (1 mg/mouse) at days 1, 3, 5, and 7 and infected with $3 \times 10^{5}$ CFUs of WT C. albicans at day 8 . The weights (B) and IL-10 protein levels (C) of the thymus were determined. The numbers of T-cell subpopulations (D), the percentages of Annexin $\mathrm{V}^{+}$and caspase $3^{+} \mathrm{CD} 4^{+} \mathrm{CD} 8^{+}$cells (E) in the thymus at day 10 and the number of naive T cells $(\mathbf{F})$ in the spleen at day 14 were analyzed by flow cytometry. Bars, mean \pm SEM. ${ }^{*} p<0.05,{ }^{* *} p<0.01,{ }^{* * *} p<0.001$, ns not significant, determined by the log rank (Mantel-Cox) test (A) or one-way ANOVA (B, C, D, E, F). Similar results were obtained in at least two independent experiments

primary lymphoid organ in which bone marrow-derived T-cell precursors undergo differentiation, ultimately leading to the migration of positively selected thymocytes to the T-celldependent areas of peripheral lymphoid organs. ${ }^{44}$ Recent studies show that normal thymocyte development and export can be altered as a result of different infectious diseases caused by viruses, protozoa, and fungi. ${ }^{20}$ One common feature is the severe atrophy of the infected thymus, mainly due to the apoptosisrelated depletion of immature CD4+ CD8 + T cells. ${ }^{21}$ As expected, our study showed that systemic infection with $C$. albicans caused severe thymus atrophy by inducing the apoptosis of immature $\mathrm{CD}^{+}{ }^{+} \mathrm{CD} 8{ }^{+}$and mature $\mathrm{CD}^{+}$or $\mathrm{CD}^{+} \mathrm{T}$ cells. During normal thymocyte development, $80 \%$ of the total thymocyte population is CD4+ CD8 + T cells, whereas C. albicans infection reduces the percentage of CD4+ CD8+ T cells to $\sim 60 \%$ of the whole population. Furthermore, we found that $C$. albicans infection significantly increased the percentage of thymic $T$ cells expressing apoptosis-related markers, including Annexin $V$ and caspase-3, by increasing the expression levels of proapoptosis-related genes (GILZ and Bim) and decreasing the expression levels of antiapoptosis-related genes $(\mathrm{BCl} 2$ and $\mathrm{BCL}-\mathrm{XL}){ }^{27,45}$ However, we surprisingly found that priming with the flo 8 null mutant or mannans extracted from serum-induced flo8 mutant cells could completely block C. albicans-induced thymus atrophy by inhibiting the apoptosis of thymic T cells. More importantly, our study showed that the flo8 mutant or mannans extracted from serum-induced flo 8 mutant cells could induce high levels of the anti-inflammatory cytokine IL-10 to increase the expression of $\mathrm{Bcl} 2$ and BCL-XL and decrease the expression of GILZ and Bim, ultimately resulting in decreased percentages and numbers of Annexin V- and caspase-3-expressing T cells. Conversely, blockade of IL-10R using its specific antibody or deficiency in the mouse thymus could completely inhibit the protective immune responses induced by the flo 8 mutant or mannans extracted from seruminduced flo8 mutant cells. Recent studies have demonstrated that IL-10 can suppress lymphocyte apoptosis partially by upregulating $\mathrm{BCl}-2$ expression, which is associated with the improved survival of septic mice and indicates that prevention of thymocyte apoptosis may contribute to the advantageous outcome and be a potential therapeutic target. ${ }^{27,28}$ It is difficult to evaluate the direct effect of thymus atrophy on the immune system, but a previous study reported that newly activated cells migrating from the thymus are critical for the sustainment of antiviral immunity. ${ }^{46}$ In addition, thymic atrophy caused by chronic virus infection impairs negative selection to facilitate the escape of self-reactive T cells. ${ }^{47}$

Sepsis is the systemic inflammatory response syndrome caused by bacterial, viral, or fungal infections. ${ }^{1}$ Although hundreds of clinical trials have been conducted, no effective new therapies 
Q.-Z. Lv et al.

A
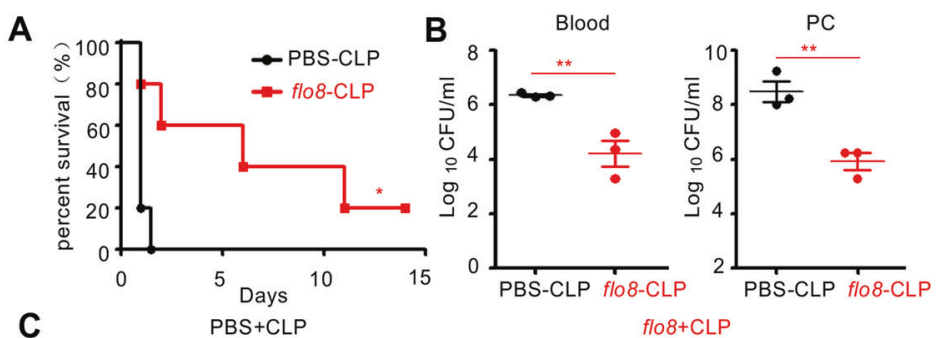

C

D

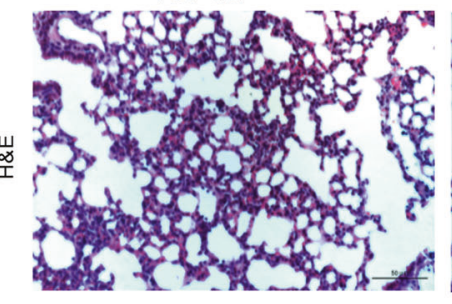

flo8+CLP
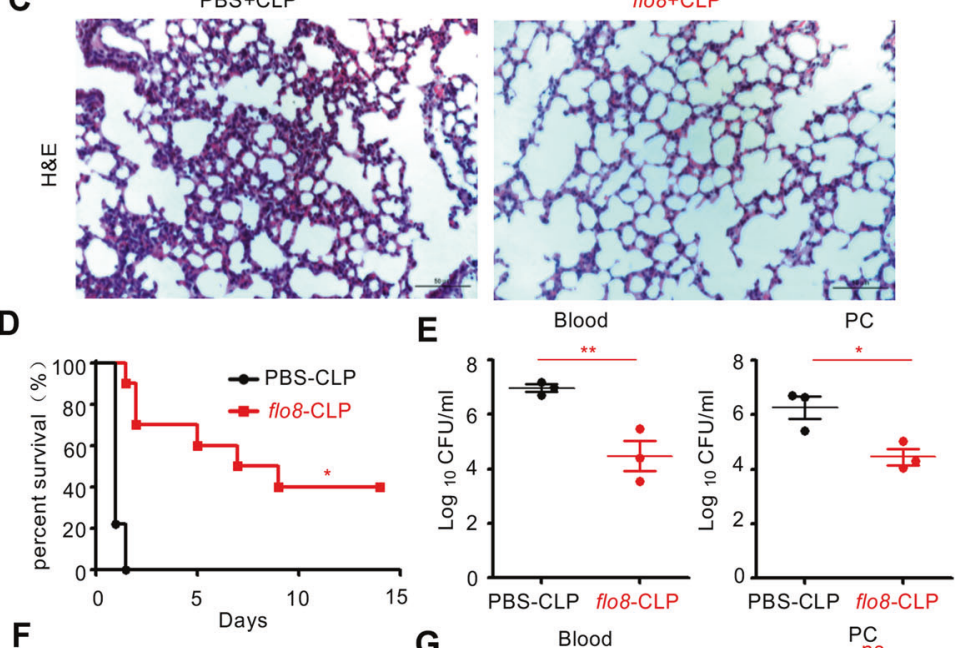

$\mathbf{F}$

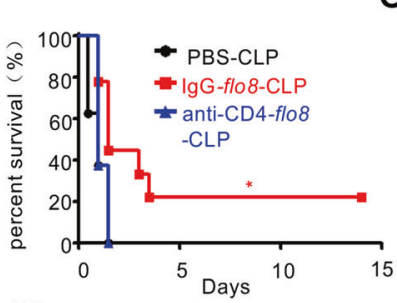

H 100
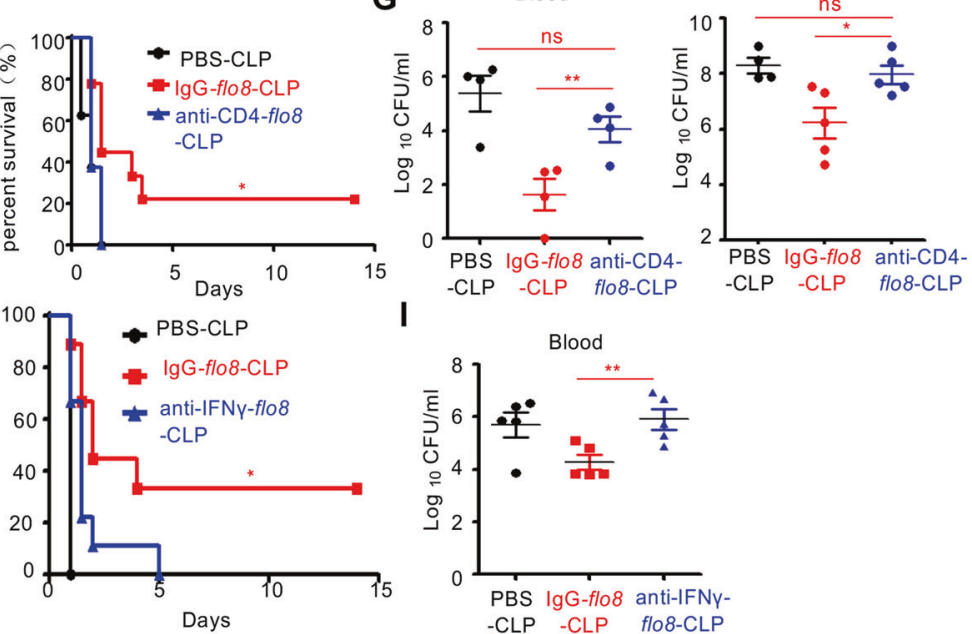

I
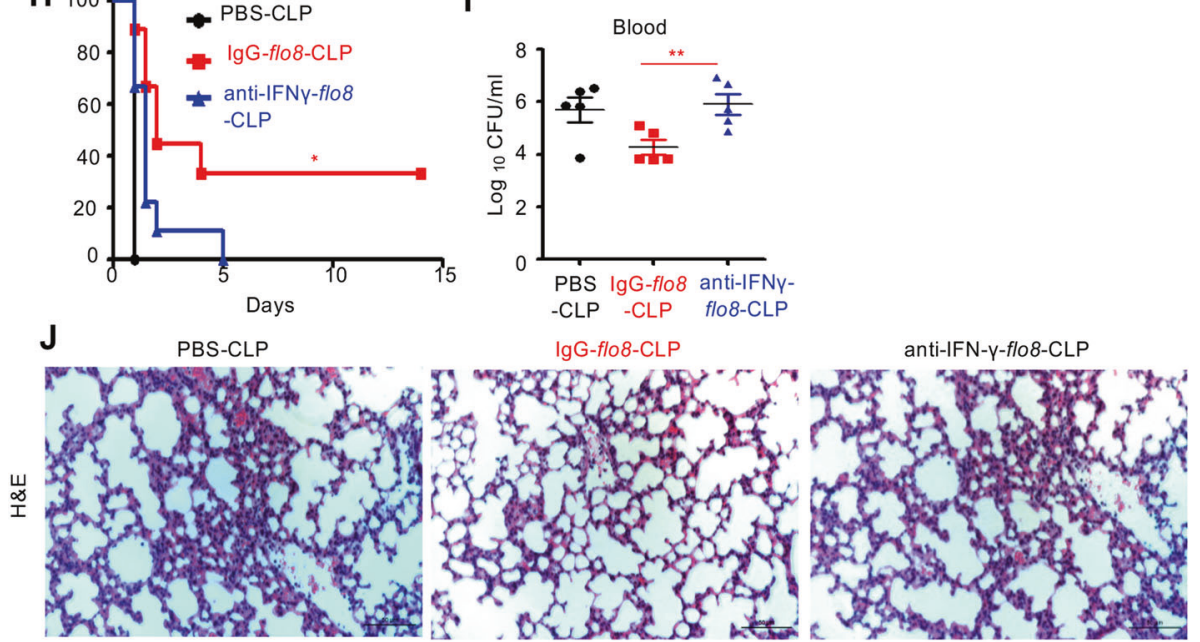

Fig. 7 Pre-exposure to the flo 8 mutant protects mice from subsequent lethal polymicrobial sepsis caused by CLP. A-C Mice were preinfected with $5 \times 10^{5}$ CFUs of the flo8 mutant or with PBS for 28 days and then subjected to CLP. The survival curves (A) and microbial burdens in the blood or peritoneal cavity (PC) were determined (B), and H\&E-stained sections of lungs from septic mice induced by CLP are shown. D, E Mice in the flo8 pre-exposure group were preinfected with $5 \times 10^{5}$ CFUs of the flo8 mutant or with PBS for 7 days and then subjected to CLP. The survival curves (D) and microbial burdens in the blood or peritoneal cavities (PCS) (E) of septic mice induced by CLP were determined. F, G Mice preinfected with the flo8 mutant were injected i.p. with $200 \mu \mathrm{g}$ of IgG or anti-mouse CD4 antibodies 1 day before C. albicans infection. The survival curves (F) and microbial burdens in the blood or peritoneal cavities (PCs) (G) of mice were determined. H-J Mice preinfected with the flo8 mutant were injected i.p. with $200 \mu \mathrm{g}$ of IgG or anti-mouse IFN- $\gamma$ antibodies on the day of C. albicans infection and at 3-day intervals thereafter until the completion of the experiment. Survival curves (H), microbial burdens in the blood (I), and H\&E-stained sections of lungs (J) from septic mice induced by CLP are shown. $n=8-10$ for the survival curves, and $n=3-5$ for the microbial burden. Bars, mean \pm SEM. ${ }^{*} p<0.05,{ }^{* *} p<0.01,{ }^{* * *} p<0.001$, PC peritoneal cavity 
against sepsis have been approved. Priming with live attenuated vaccines or commensal microorganisms is increasingly being recognized to improve many aspects of the host immune system. $^{4-6,48-50}$ Here, we show that prior inocuation of FLO8deficient $C$. albicans could effectively protect mice from polymicrobial sepsis induced by CLP. The protection depends on Th1mediated adaptive immune responses. The immunopotentiating effect of the flo 8 mutant makes it a live attenuated vaccine capable of preventing polymicrobial infections.

Collectively, our data imply that Flo8p, a key transcription factor for regulating the yeast-to-hyphae transition of $C$. albicans, has potential to be both an antifungal and immunotherapeutic target, and mannans extracted from the cell wall of the flos null mutant strain may provide potential immunotherapeutic candidate(s) for controlling fatal infectious diseases.

\section{MATERIALS AND METHODS}

Fungi, media and growth conditions

C. albicans strains SC5314 (WT), UCA3, UCA21, flo8 (FLO8 $\Delta / \Delta)$, flo8 + FLO8 (FLO8 $\Delta / F L O 8)$, and efg1/cph1 (EFG1 $/ \Delta C P H 1 \Delta / \Delta)$ were grown overnight in YPD-rich medium at $30^{\circ} \mathrm{C}$. UV- and heat-killed C. albicans strains were exposed to $1000 \mathrm{~J} / \mathrm{cm}^{2}$ of UV 5 times in a $\mathrm{CL}-1000$ cross-linker and to a $95^{\circ} \mathrm{C}$ water bath for $10 \mathrm{~min}$, respectively. $C$. albicans yeast cells were incubated with YNB plus $10 \%$ FBS at $37^{\circ} \mathrm{C}$ for $3 \mathrm{~h}$. The C. albicans strains used in this study are listed in Table S1.

\section{Preparation of BMDMs and BMDCs}

For BMDM preparation, bone marrow cells isolated from 6- to 8week-old female mice were cultured in medium containing M-CSF medium, $10 \%$ FBS and $30 \%$ of the culture supernatant from L929 cells. Fresh M-CSF-containing medium was added on day 3 , and the fully differentiated BMDMs were harvested on day 6 for the functional assay.

BMDCs were generated by cultivating murine bone marrow cells $\left(1 \times 10^{6}\right.$ cells $\left./ \mathrm{ml}\right)$ from 6 - to 8 -week-old female mice in growth medium supplemented with recombinant M-CSF (40 ng/ $\mathrm{ml}$ ). The culture medium was replaced every 2 days, and the fully differentiated DCs were harvested on day 8 for the functional assay.

\section{Mice}

C57BL/6, Balb/c, and nude mice were purchased from Shanghai SLAC Laboratory Animal Co, Ltd. Clec $7 a^{-1-}$, Clec $4 n^{-1-}$, Clec4 $e^{-1-}$, $\mathrm{Card}^{-1-}$, and $\mathrm{Rag}^{-1-}$ mice were maintained at Tongji University Animal Center. All mice were genotyped by PCR using genomic tail DNA. All mice were housed under specific pathogen-free conditions at Tongji University. All animal experiments were performed in compliance with institutional guidelines and according to the protocol approved by the Institutional Animal Care and Use Committee of Tongji University.

Primary infection and reinfection models

Six- to eight-week-old female mice were challenged i.v. with live or dead flo 8 mutant strains at $2.5 \times 10^{6} \mathrm{CFUs} / \mathrm{ml}$. After 7 or 14 days of inoculation, the mice were reinfected i.v. with the same dose of the flo8 mutant, WT C. albicans SC5314, or clinically isolated UCA3 or UCA21 strain. Survival of the reinfected mice was observed for 30 days. For the immunoprotection of mannans, mice infected with WT C. albicans SC5314 strains were injected intraperitoneally with $1 \mathrm{mg}$ of mannans extracted from flo 8 mutant strains at days $1,3,5$, and 7. For IL-10R blocking, mice inoculated with $5 \times 10^{5}$ CFUs of flo8 mutant cells were injected intraperitoneally with 300 $\mu \mathrm{g}$ of anti-CD210 antibodies or lgG at days 1,3,5, and 7. Then, the mice were reinfected i.v. with $5 \times 10^{5}$ CFUs of WT C. albicans SC5314 strains and received $300 \mu \mathrm{g}$ of anti-CD210 antibodies at day 8 . On day 9 , the mice were sacrificed, and thymocytes were collected for flow cytometry and RT-PCR analysis. For $\mathrm{CD}^{+}{ }^{+} \mathrm{T}$-cell depletion, mice were injected i.p. with $200 \mu \mathrm{g}$ of an anti-CD4 antibody (clone GK1.5) one day before C. albicans infection. For IFN- $\gamma$ neutralization, mice were injected i.p. with $200 \mu \mathrm{g}$ of an antiIFN- $\gamma$ antibody (clone XMG1.2) on the day of $C$. albicans infection and reinjected at 3-day intervals until the completion of the experiment.

\section{Sepsis model}

The sepsis model was generated by injection of $10 \mathrm{mg} / \mathrm{kg}$ LPS (i.p.) or cecum ligation and puncture (CLP) as described previously. ${ }^{35}$ Briefly, mice were anesthetized with $1 \%$ pentobarbital solution, and a midline abdominal incision was performed. The ileocecal valve was ligated on the distal 3/4 end of the cecum. The cecum was perforated by a through and through puncture with an $18 \mathrm{G}$ needle. A feces droplet was extruded from the hole to induce polymicrobial sepsis. The abdominal wall was sutured, and the mice were injected s.c. with $1 \mathrm{ml}$ of $0.9 \% \mathrm{NaCl}$ for fluid resuscitation.

\section{Recoverable microbial burden}

The viable microorganisms in infected organs were determined by counting the number of colony-forming units (CFUs). The spleen, liver, or kidneys were harvested from mice infected with $C$. albicans. The homogenized organs were diluted with PBS and plated on SDA agar. CFUs were counted after incubation at $30^{\circ} \mathrm{C}$ for $48 \mathrm{~h}$.

Blood and peritoneal fluid from septic mice were collected, diluted, and plated on $\mathrm{MHI}$ agar. Microbial burdens were counted after incubation at $37^{\circ} \mathrm{C}$ for $24 \mathrm{~h}$.

\section{Cytokine measurement}

The serum and supernatants of homogenized thymus, spleen, and kidney organs from mice infected with $C$. albicans were collected. The supernatants were collected from splenic cells, which were seeded in 96-well U-shaped plates at a density of $1 \times 10^{6}$ cells/well and cultured at $37^{\circ} \mathrm{C}$ for $48 \mathrm{~h}$. The protein levels of IL-10, IFN- $\gamma$, IL17A, IL-6, and TNF-a were measured using mouse ELISA kits (eBioscience) according to the manufacturer's instructions.

BMDMs and BMDCs were stimulated with UV-killed C. albicans for $16 \mathrm{~h}$. Then, the supernatants were collected for enzyme-linked immunosorbent assays (ELISAs), which were performed to assess the indicated cytokines according to the manufacturer's instructions.

RNA isolation and quantitative reverse transcription PCR Mice infected with C. albicans strains for $24 \mathrm{~h}$ were sacrificed. The cells from the thymus were harvested and counted. Total RNA was isolated using $1 \mathrm{ml}$ of TRlzol (Takara) according to the manufacturer's protocol. RNA (500 ng) was reverse transcribed with PrimeScript $^{\mathrm{TM}}$ RT Master Mix. RT-PCR was performed using SYBR ${ }^{\circ}$ Premix Ex Taq ${ }^{\mathrm{TM}}$ II. GAPDH served as the housekeeping gene, and the expression of genes was calculated by $\Delta \Delta \mathrm{Ct}$.

\section{Cell staining and flow cytometry}

Single-cell suspensions of thymus or spleen organs harvested from uninfected or infected mice were prepared. For detecting apoptosis, cells were incubated with FITC-CD45, V450-CD4, APC$\mathrm{CD} 8 \mathrm{a}$, and Annexin $\mathrm{V}$ antibodies in the binding buffer at room temperature for $20 \mathrm{~min}$. Then, the cells were washed with PBS + $2 \%$ FBS twice and treated with $5 \mu$ of 7-AAD in $100 \mu$ l of binding buffer for $15 \mathrm{~min}$. After washing with $500 \mu$ l of $1 \times$ binding buffer, the cells were filtered into flow tubes and analyzed by $B D$ FACSverse. To detect caspase-3 expression, cells were stained with FITC-CD45, APC-CD8a, and V450-CD4 antibodies. Then, the cells were washed with PBS and incubated with $1 \mathrm{ml}$ of BD Cytofix/ Cytoperm solution for 20 min on ice. Subsequently, the cells were stained with PE-caspase 3 antibodies at room temperature for 30 
min. After washing with $1 \times$ Perm/wash buffer, the cells were filtered into flow tubes and analyzed by BD FACSreverse. To detect naive $T$ cells, splenic cells were stained with living dye as well as FITC-CD3, V450-CD4, APC-CD8, and PerCP 5.5-CD62L antibodies on ice for $20 \mathrm{~min}$ and washed with PBS $+2 \%$ FBS. For detecting Th1 cells, splenic cells were obtained as described above and stimulated with phorbol 12-myristate 13 -acetate (PMA, $50 \mu \mathrm{g} / \mathrm{ml}$ ) and ionomycin $(1 \mu \mathrm{M})$ for $5 \mathrm{~h}$ in the presence of brefeldin $\mathrm{A}(5 \mathrm{mg} /$ $\mathrm{ml})$. Surface staining was performed, followed by intracellular staining for IFN- $\gamma$ or IL-17A using the BD Cytofix/Cytoperm Kit (BD Biosciences). After washing with PBS, cells were filtered into flow tubes and analyzed by BD FACSreverse, and data were analyzed with FlowJo (Tree Star).

Mannans staining by ConA-Alexa Fluor 48 Conjugate

Yeast C. albicans was cultured in YNB medium at $30^{\circ} \mathrm{C}$ overnight. Serum-induced C. albicans were cultured in YNB $+10 \%$ FBS medium at $37^{\circ} \mathrm{C}$ for $3 \mathrm{~h}$. After washing three times with PBS, $1 \times 10^{7}$ cells were fixed with $4 \%$ paraformaldehyde for $1 \mathrm{~h}$. The cells were washed three times with PBS and stained with $500 \mu \mathrm{l}$ of $50 \mu \mathrm{g} / \mathrm{ml}$ ConA-Alexa Fluor 48 Conjugate at $30^{\circ} \mathrm{C}$ for $1 \mathrm{~h}$. After incubation, the cells were washed five times with PBS and analyzed by BD FACSverse.

Mannan disruption by acid or alkali

C. albicans flo8 mutants were cultured in YNB $+10 \%$ FBS medium at $37^{\circ} \mathrm{C}$ for $3 \mathrm{~h}$ in $5 \% \mathrm{CO}_{2}$. The cells were collected, washed, and counted. A total of $1 \times 10^{8}$ cells were resuspended in PBS, $2 \%(\mathrm{w} / \mathrm{v})$ $\mathrm{NaOH}$ or $10 \mathrm{mM} \mathrm{HCl}$ and then heated in a $95^{\circ} \mathrm{C}$ water bath for 15 min. Then, the cells were collected for the following experiments.

\section{Extraction of C. albicans mannans}

Mannans from C. albicans were extracted as previously described. ${ }^{51}$ Briefly, yeast mannans (YM) were extracted from C. albicans cultured in YNB medium for $24 \mathrm{~h}$ at $30^{\circ} \mathrm{C}$. Induced mannans (IM) were extracted from $C$. albicans grown in YNB + $10 \%$ FBS medium for $3 \mathrm{~h}$ at $37^{\circ} \mathrm{C}$ in $5 \% \mathrm{CO}_{2}$. C. albicans cells $(1 \mathrm{~g}$ wet weight) were heated in $4 \mathrm{ml}$ of $2 \%$ (wt/vol) $\mathrm{NaOH}$ solution for $1 \mathrm{~h}$ at $100^{\circ} \mathrm{C}$. After centrifugation, the supernatant was collected. Mannans were precipitated from the cold supernatant with fresh Fehling's reagent. The precipitate was dissolved in a $3 \mathrm{M} \mathrm{HCl}$ solution. Subsequently, a solution of methanol and acetic acid mixed at a ratio of 8:1 ( $\mathrm{vol} / \mathrm{vol})$ was added to the mannnans in the solution. The processes of dissolution and precipitation were performed twice. After that, the precipitate was centrifuged and dissolved in distilled water. Finally, mannans were dialyzed for 24 $\mathrm{h}$ in $\mathrm{dd}_{2} \mathrm{O}$. The protein levels of purified mannans were less than $0.5 \%$, as determined by the Micro BCA Protein Assay Kit. The endotoxin concentration of extracted mannans was $\sim 0.35 \mathrm{EU} / \mathrm{mg}$, as determined by the ToxinSensor Chromogenic LAL Endotoxin Assay Kit.

\section{Monosaccharide composition analysis by GC-MS}

Monosaccharide standards (D-galactose, D-arabinose, L-rhamnose, L-fucose, D-mannose, D-xylose, and D-glucose) were treated as described previously. ${ }^{52,53}$ Two milligrams of extracted mannans or monosaccharide standards were hydrolyzed with $2 \mathrm{M}$ trifluoroacetic acid at $121^{\circ} \mathrm{C}$ for $2 \mathrm{~h}$. After evaporation, the residue was dissolved in $200 \mu \mathrm{l} \mathrm{of} \mathrm{H}_{2} \mathrm{O}$ and reduced with $1 \mathrm{ml}$ of $0.5 \mathrm{~mol} / \mathrm{l}$ $\mathrm{NaBH}_{4}$ DMSO solution at $40^{\circ} \mathrm{C}$ for 90 min. Then, glacial acetic acid was added dropwise to the reaction tubes. The residue was acetylated with $200 \mu \mathrm{l}$ of 1-methylimidazole and $1 \mathrm{ml}$ of acetic anhydride at $40{ }^{\circ} \mathrm{C}$ for $30 \mathrm{~min}$ to obtain the acetylated derivatives, which were then extracted with $2 \mathrm{ml}$ of chloroform. The chloroform layer was washed three times with $\mathrm{dd}_{2} \mathrm{O}$. Subsequently, the chloroform layer was dried by anhydrous sodium sulfate and analyzed by an Agilent Technologies 7890B-5977A GC/MSD system. The temperature profile started at $120^{\circ} \mathrm{C}$ and increased to $190^{\circ} \mathrm{C}$ at $3^{\circ} \mathrm{C} / \mathrm{min}$, followed by a $2^{\circ} \mathrm{C} / \mathrm{min}$ gradient up to $250^{\circ} \mathrm{C}$, where it was held for $5 \mathrm{~min}$.

\section{ACKNOWLEDGEMENTS}

This work was supported by the National Natural Science Foundation of China (31970889, 31622023 to X.M.J. and 81902039 to Q.Z.L.), the Innovation Program of Shanghai Municipal Education Commission (201901070007E00022 to X.M.J.), the Outstanding Academic Leader Program of the Shanghai Health and Family Planning Commission (2017BR024 to X.M.J.), the Shuguang Program of the Shanghai Municipal Education Commission (17SG24 to X.M.J.), the Fundamental Research Funds for the Central Universities (X.M.J.) and by a member of the Innovative Research Team of High-Level Local University in Shanghai (X.M.J.), the Key fund for basic research of Shanghai Science and Technology Commission (20JC1417700 to X.M.J.), Shanghai Municipal Natural Science Foundation (19ZR1461800 to D.D.L.).

\section{AUTHOR CONTRIBUTIONS}

Q.Z.L. and X.M.J. designed the experiments. Q.Z.L., D.D.L., H.H., and Y.H.Y. performed the experiments. J.L.D., H.H.M., Y.Y., J.Y.C., and Y.Y.J. contributed critical reagents. Q.Z.L. and X.M.J. wrote the manuscript with editorial input from all the authors.

\section{ADDITIONAL INFORMATION}

The online version of this article (https://doi.org/10.1038/s41423-020-00576-6) contains supplementary material.

Competing interests: The authors declare no competing interests.

\section{REFERENCES}

1. Kaukonen, K. M., Bailey, M., Pilcher, D., Cooper, D. J. \& Bellomo, R. Systemic inflammatory response syndrome criteria in defining severe sepsis. N. Engl. J. Med 372, 1629-1638 (2015).

2. Posch, W., Steger, M., Wilflingseder, D. \& Lass-Florl, C. Promising immunotherapy against fungal diseases. Expert Opin. Biol. Ther. 17, 861-870 (2017).

3. Nami, S., Aghebati-Maleki, A., Morovati, H. \& Aghebati-Maleki, L. Current antifungal drugs and immunotherapeutic approaches as promising strategies to treatment of fungal diseases. Biomed. Pharmacother. 110, 857-868 (2019).

4. de Bree, L. C. J. et al. Non-specific effects of vaccines: current evidence and potential implications. Semin. Immunol. 39, 35-43 (2018).

5. Netea, M. G. et al. Trained immunity: a program of innate immune memory in health and disease. Science 352, aaf1098 (2016).

6. Jiang, T. T. et al. Commensal fungi recapitulate the protective benefits of intestinal bacteria. Cell Host Microbe 22, 809-816. e804 (2017).

7. Wilson, D., Naglik, J. R. \& Hube, B. The missing link between Candida albicans hyphal morphogenesis and host cell damage. PLoS Pathog. 12, e1005867 (2016).

8. Kullberg, B. J. \& Arendrup, M. C. Invasive candidiasis. N. Engl. J. Med. 373, 1445-1456 (2015).

9. Pappas, P. G., Lionakis, M. S., Arendrup, M. C., Ostrosky-Zeichner, L. \& Kullberg, B. J. Invasive candidiasis. Nat. Rev. Dis. Prim. 4, 18026 (2018).

10. Noble, S. M., Gianetti, B. A. \& Witchley, J. N. Candida albicans cell-type switching and functional plasticity in the mammalian host. Nat. Rev. Microbiol. 15, 96-108 (2017).

11. Cao, F. et al. The Flo8 transcription factor is essential for hyphal development and virulence in Candida albicans. Mol. Biol. Cell 17, 295-307 (2006).

12. Gross, O. et al. Card 9 controls a non-TLR signalling pathway for innate anti-fungal immunity. Nature 442, 651-656 (2006).

13. Alves de Medeiros, A. K. et al. Chronic and invasive fungal infections in a family with CARD9 deficiency. J. Clin. Immunol. 36, 204-209 (2016).

14. Zhu, L. L. et al. C-type lectin receptors Dectin-3 and Dectin-2 form a heterodimeric pattern-recognition receptor for host defense against fungal infection. Immunity 39, 324-334 (2013).

15. Jia, X. M. et al. CARD9 mediates Dectin-1-induced ERK activation by linking RasGRF1 to H-Ras for antifungal immunity. J. Exp. Med. 211, 2307-2321 (2014).

16. Thompson, A. et al. The protective effect of inflammatory monocytes during systemic C. albicans infection is dependent on collaboration between C-type lectin-like receptors. Plos Pathog. 15, e1007850 (2019).

17. Ryan, O. et al. Global gene deletion analysis exploring yeast filamentous growth. Science 337, 1353-1356 (2012).

18. Lewis, R. E., Lo, H. J., Raad, I. I. \& Kontoyiannis, D. P. Lack of catheter infection by the efg1/efg1 cph1/cph1 double-null mutant, a Candida albicans strain that is defective in filamentous growth. Antimicrob. Agents Chemother. 46, 1153-1155 (2002). 
19. Brand, A. Hyphal growth in human fungal pathogens and its role in virulence. Int J. Microbiol 2012, 517529 (2012).

20. Nunes-Alves, C., Nobrega, C., Behar, S. M. \& Correia-Neves, M. Tolerance has its limits: how the thymus copes with infection. Trends Immunol. 34, 502-510 (2013).

21. Savino, W. The thymus is a common target organ in infectious diseases. PLoS Pathog. 2, e62 (2006).

22. Wesche, D. E., Lomas-Neira, J. L., Perl, M., Chung, C. S. \& Ayala, A. Leukocyte apoptosis and its significance in sepsis and shock. J. Leukoc. Biol. 78, 325-337 (2005).

23. Hotchkiss, R. S., Monneret, G. \& Payen, D. Immunosuppression in sepsis: a novel understanding of the disorder and a new therapeutic approach. Lancet Infect. Dis. 13, 260-268 (2013).

24. Freitas, A. A., Rocha, B. \& Coutinho, A. A. Lymphocyte population kinetics in the mouse. Immunol. Rev. 91, 5-37 (1986).

25. den Braber, I. et al. Maintenance of peripheral naive T cells is sustained by thymus output in mice but not humans. Immunity 36, 288-297 (2012).

26. Douek, D. C. et al. Changes in thymic function with age and during the treatment of HIV infection. Nature 396, 690-695 (1998).

27. Oberholzer, C. et al. Targeted adenovirus-induced expression of IL-10 decreases thymic apoptosis and improves survival in murine sepsis. Proc. Natl Acad. Sci. USA 98, 11503-11508 (2001).

28. Tschoeke, S. K. et al. Endogenous IL-10 regulates sepsis-induced thymic apoptosis and improves survival in septic IL-10 null mice. Scand. J. Immunol. 68, 565-571 (2008).

29. Coopersmith, C. M. et al. Overexpression of $\mathrm{Bcl}-2$ in the intestinal epithelium improves survival in septic mice. Crit. Care Med. 30, 195-201 (2002).

30. Latifi, S. Q., O'Riordan, M. A. \& Levine, A. D. Interleukin-10 controls the onset of irreversible septic shock. Infect. Immun. 70, 4441-4446 (2002).

31. Kato, T. et al. Interleukin 10 reduces mortality from severe peritonitis in mice. Antimicrob. Agents Chemother. 39, 1336-1340 (1995).

32. Lowman, D. W. et al. Novel structural features in Candida albicans hyphal glucan provide a basis for differential innate immune recognition of hyphae versus yeast. J. Biol. Chem. 289, 3432-3443 (2014).

33. Shibata, N., Suzuki, A., Kobayashi, H. \& Okawa, Y. Chemical structure of the cellwall mannan of Candida albicans serotype $A$ and its difference in yeast and hyphal forms. Biochem. J. 404, 365-372 (2007).

34. Zhang, S. Q. et al. Mnn10 maintains pathogenicity in Candida albicans by extending alpha-1,6-mannose backbone to evade host Dectin-1 mediated antifungal immunity. PLoS Pathog. 12, e1005617 (2016).

35. Rittirsch, D., Huber-Lang, M. S., Flierl, M. A. \& Ward, P. A. Immunodesign of experimental sepsis by cecal ligation and puncture. Nat. Protoc. 4, 31-36 (2009).

36. Vila, T. et al. Targeting Candida albicans filamentation for antifungal drug development. Virulence 8, 150-158 (2017).

37. Saville, S. P., Lazzell, A. L., Chaturvedi, A. K., Monteagudo, C. \& Lopez-Ribot, J. L. Efficacy of a genetically engineered Candida albicans tet-NRG1 strain as an experimental live attenuated vaccine against hematogenously disseminated candidiasis. Clin. Vaccin. Immunol. 16, 430-432 (2009).

38. Bistoni, F. et al. Evidence for macrophage-mediated protection against lethal Candida albicans infection. Infect. Immun. 51, 668-674 (1986).

39. Montagnoli, C. et al. B7/CD28-dependent CD4+CD25+ regulatory $T$ cells are essential components of the memory-protective immunity to Candida albicans. J. Immunol. 169, 6298-6308 (2002).
40. Hontelez, S., Sanecka, A., Netea, M. G., van Spriel, A. B. \& Adema, G. J. Molecular view on PRR cross-talk in antifungal immunity. Cell Microbiol. 14, 467-474 (2012).

41. Netea, M. G., Brown, G. D., Kullberg, B. J. \& Gow, N. A. An integrated model of the recognition of Candida albicans by the innate immune system. Nat. Rev. Microbiol. 6, 67-78 (2008).

42. Lin, L. et al. Th1-Th17 cells mediate protective adaptive immunity against Staphylococcus aureus and Candida albicans infection in mice. PLoS Pathog. 5, e1000703 (2009).

43. Quintin, J. et al. Candida albicans infection affords protection against reinfection via functional reprogramming of monocytes. Cell Host Microbe 12, 223-232 (2012).

44. Klein, L., Kyewski, B., Allen, P. M. \& Hogquist, K. A. Positive and negative selection of the T cell repertoire: what thymocytes see (and don't see). Nat. Rev. Immunol. 14, 377-391 (2014)

45. Sionov, R. V., Vlahopoulos, S. A. \& Granot, Z. Regulation of Bim in health and disease. Oncotarget 6, 23058-23134 (2015).

46. Vezys, V. et al. Continuous recruitment of naive T cells contributes to heterogeneity of antiviral CD8 T cells during persistent infection. J. Exp. Med. 203, 2263-2269 (2006).

47. Elsaesser, H. J. et al. Chronic virus infection drives CD8 T cell-mediated thymic destruction and impaired negative selection. Proc. Natl Acad. Sci. USA 117, 5420-5429 (2020).

48. Abt, M. C. et al. Commensal bacteria calibrate the activation threshold of innate antiviral immunity. Immunity 37, 158-170 (2012).

49. Ichinohe, $\mathrm{T}$. et al. Microbiota regulates immune defense against respiratory tract influenza A virus infection. Proc. Natl Acad. Sci. USA 108, 5354-5359 (2011).

50. Chung, H. \& Kasper, D. L. Microbiota-stimulated immune mechanisms to maintain gut homeostasis. Curr. Opin. Immunol. 22, 455-460 (2010).

51. van de Veerdonk, F. L. et al. The macrophage mannose receptor induces IL-17 in response to Candida albicans. Cell Host Microbe 5, 329-340 (2009).

52. Li, K. et al. Identification of cultured and natural astragalus root based on monosaccharide mapping. Molecules 20, 16466-16490 (2015).

53. Li, X. J. et al. Chemical structure and immunomodulating activities of an alphaglucan purified from Lobelia chinensis Lour. Molecules 21, 779 (2016).

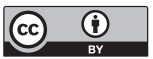

Open Access This article is licensed under a Creative Commons Attribution 4.0 International License, which permits use, sharing, adaptation, distribution and reproduction in any medium or format, as long as you give appropriate credit to the original author(s) and the source, provide a link to the Creative Commons license, and indicate if changes were made. The images or other third party material in this article are included in the article's Creative Commons license, unless indicated otherwise in a credit line to the material. If material is not included in the article's Creative Commons license and your intended use is not permitted by statutory regulation or exceeds the permitted use, you will need to obtain permission directly from the copyright holder. To view a copy of this license, visit http://creativecommons. org/licenses/by/4.0/.

(c) CSI and USTC 2020 